\title{
Experiências de educação interprofissional no contexto das residências multiprofissionais em saúde: estudo de revisão
}

\author{
Interprofessional education experiences in the context of multiprofessional residencies in health: a \\ review study
}

Experiencias de educación interprofesional en el contexto de las residencias multiprofesionales en salud: un estudio de revisión

Recebido: 08/01/2022 | Revisado: 13/01/2022 | Aceito: 19/01/2022 | Publicado: 06/02/2022

\author{
Lidiane de Freitas Sarmento \\ ORCID: https://orcid.org/0000-0002-0221-6548 \\ Universidade do Estado do Rio de Janeiro, Brasil \\ E-mail: lidianefsarmento@gmail.com \\ Tania França \\ ORCID: https://orcid.org/0000-0002-8209-9811 \\ Universidade do Estado do Rio de Janeiro, Brasil \\ E-mail: taniafranca29@gmail.com \\ Carinne Magnago \\ ORCID: https://orcid.org/0000-0001-8799-3225 \\ Universidade de São Paulo, Brasil \\ E-mail: carinne.mag@gmail.com
}

\begin{abstract}
Resumo
As Residências Multiprofissionais em Saúde (RMS) vêm sendo cada vez mais consideradas como uma importante alternativa de formação dos profissionais de saúde para o arranjo de novos desenhos tecnoassistenciais. A Educação Interprofissional em Saúde (EIP) ocorre quando duas ou mais profissões aprendem com, a partir e sobre a outra com o objetivo comum de melhorar a colaboração no trabalho em equipe. Pode se inserir no contexto das pós-graduações, incluindo as RMS, visando à materialização das práticas colaborativas e à melhoria dos resultados em saúde. Este estudo objetivou identificar experiências relacionadas às práticas de EIP adotadas nos cenários das RMS em âmbito nacional. Foi realizada revisão integrativa da literatura e considerados os estudos publicados em português, inglês ou espanhol, no período entre 2010 e 2020, que versassem sobre a EIP no âmbito das RMS no Brasil. Foram incluídos 37 estudos e, de acordo com seus objetivos, foram identificadas três categorias que caracterizam a produção científica sobre o tema: "RMS como cenários para a promoção da EIP e das práticas colaborativas", "RMS e o desenvolvimento de competências para o trabalho interprofissional e transformação das práticas" e "Limites e desafios à EIP nas RMS". Os estudos encontrados se concentraram em analisar as percepções dos atores das RMS sobre princípios e práticas da EIP; analisar instrumentos institucionais das RMS pela perspectiva da EIP; e descrever experiências de implantação e desenvolvimento de atividades e práticas interprofissionais nas RMS.
\end{abstract}

Palavras-chave: Residências multiprofissionais em saúde; Educação interprofissional; Colaboração profissional; Teamwork.

\begin{abstract}
Multiprofessional Residencies in Health (RMS) have been increasingly considered as an important training alternative for health professionals for the arrangement of new techno-assistance designs. Interprofessional Health Education (IPE) occurs when two or more professions learn about, from, and with other with the common goal of improving collaboration in teamwork. It can be inserted in the context of postgraduate courses, including the RMS, aiming at the materialization of collaborative practices and the improvement of health outcomes. This study aimed to identify experiences related to IPE practices adopted in RMS scenarios at the national level. The integrative literature review method was used. Were considered studies published in Portuguese, English or Spanish, between 2010 and 2020, that dealt with IPE within the scope of RMS in Brazil. 37 studies were included and, according to their objectives, three categories were identified that characterize the scientific production on the topic: "RMS as scenarios for the promotion of the IPE and collaborative practices", "RMS and the development of competences for work interprofessional and transformation of practices" and "Limits and challenges to IPE in RMS". The studies found focused on analyzing the perceptions of RMS actors on IPE principles and practices; analyze institutional instruments of the RMS from the perspective of the EIP; and to describe experiences of implantation and development of activities and interprofessional practices in the RMS.
\end{abstract}


Keywords: Multiprofessional residencies in health; Interprofessional education; Professional collaboration; Health education; Teaching.

\begin{abstract}
Resumen
Las Residencias Multiprofesionales en Salud (RMS) han sido consideradas cada vez más como una importante alternativa de formación de los profesionales de la salud para la disposición de nuevos diseños tecnoasistenciales. La Educación Interprofesional (EIP) ocurre cuando dos o más profesiones aprenden sobre los demás, con los demás y entre sí con el objetivo común de mejorar la colaboración en el trabajo en equipo. Puede insertarse en el contexto de cursos de posgrado, incluido el RMS, en busca de la materialización de prácticas colaborativas y la mejora de los resultados en salud. Este estudio tuvo como objetivo identificar experiencias relacionadas con las prácticas de EIP adoptadas en escenarios de RMS a nivel nacional. Se utilizó el método de revisión integrativa de la literatura. Se consideraron estudios publicados en portugués, inglés o español, entre 2010 y 2020, que trataran sobre EIP en el ámbito de la RMS en Brasil. Se incluyeron 37 estudios y, de acuerdo con sus objetivos, se identificaron tres categorías que caracterizan la producción científica sobre el tema: "RMS como escenarios para la promoción de la EIP y prácticas colaborativas", "MRS y el desarrollo de competencias para el trabajo interprofesional y transformación de prácticas" y "Límites y desafíos de la EIP en RMS". Los estudios encontrados se centraron en analizar las percepciones de los actores de la RMS sobre los principios y prácticas de la EIP; analizar los instrumentos institucionales del RMS desde la perspectiva de la EIP; y describir experiencias de implantación y desarrollo de actividades y prácticas interprofesionales en el RMS.
\end{abstract}

Palabras clave: Residencias multiprofesionales en salud; Educación interprofesional; Colaboración profesional; Trabajo en equipo.

\title{
1. Introdução
}

A implementação do Sistema Único de Saúde (SUS) e as mudanças no perfil epidemiológico brasileiro trouxeram a necessidade de se pensar a formação de profissionais capazes de lidar com as mais diversas necessidades de saúde de forma integral. O perfil dos profissionais formados para o SUS é de suma importância na medida em que estes ajudam a fortalecer a implantação de certas iniciativas e políticas em direção aos seus princípios (Peduzzi et al., 2013; Feuerwerker, 2009).

Pautadas pela integração ensino-serviço-comunidade e pela formação para o trabalho em equipe, as Residências Multiprofissionais em Saúde (RMS) possuem um papel problematizador e questionador da racionalidade estritamente técnica do ensino em saúde. Ao propor a formação de profissionais para uma atuação diferenciada no SUS, a partir da construção interdisciplinar dos profissionais em saúde, as RMS desafiam a tendência da atuação profissional isolada, individualista e fragmentada, reorientando assim as lógicas tecnoassistenciais (Casanova et al., 2015a; Feuerwerker, 2009).

É reconhecido internacionalmente que muitos sistemas de saúde no mundo estão fragmentados e com dificuldades para gerenciar as necessidades de saúde não atendidas (Organização Mundial da Saúde, 2010). A Educação Interprofissional em Saúde (EIP) para a prática colaborativa centrada no paciente vem sendo identificada como um mecanismo chave para a melhoria dos serviços de saúde prestados (Steinert, 2005).

A EIP acontece quando duas ou mais profissões juntam-se para aprender com, a partir e sobre a outra com o objetivo comum de melhorar a colaboração no trabalho em equipe e, consequentemente, a qualidade do cuidado. Está inserida no contexto universitário, em cursos e atividades realizadas na graduação e pós-graduação (Barr, 2013).

A EIP pode ser entendida como uma abordagem de aprendizagem interativa que tem como objetivo fornecer subsídios teóricos e metodológicos para assegurar a formação de profissionais mais aptos ao efetivo trabalho em equipe. Dessa forma, a EIP tem como horizonte a materialização de práticas colaborativas no âmbito das dinâmicas do trabalho em saúde (Barr, 2015).

Dentro do contexto de crise de recursos humanos no setor da saúde, a EIP deve ser vista como oportunidade para desenvolver novas habilidades e definir perfis profissionais compatíveis com as necessidades e expectativas de saúde da população (Organização Pan-Americana da Saúde, 2017). Segundo a Canadian Health Services Research Foundation (2006), sistemas de saúde que apoiam e dão suporte ao efetivo trabalho em equipe podem melhorar a qualidade de assistência, aumentar a segurança dos pacientes e reduzir a sobrecarga de trabalho entre os profissionais de saúde (Reeves et al., 2016). 
Considerando que algumas iniciativas de EIP no cenário de prática brasileiro vem sendo realizadas de forma incipiente e em diversos formatos (Costa, 2016), este artigo tem como objetivo identificar as experiências de EIP nos cenários das RMS brasileiras.

\section{Metodologia}

Trata-se de uma revisão integrativa da literatura (RIL), compreendida como um método de pesquisa que produz uma análise ampla da literatura dando suporte para a tomada de decisão, melhoria da prática clínica e apontamentos de lacunas no conhecimento científico sobre o tema. Pode incluir múltiplos estudos com diferentes delineamentos de pesquisas, proporcionando uma compreensão mais completa e profunda do tema de interesse (Mendes et al., 2008).

A RIL foi realizada conforme os passos delineados por Mendes, Silveira e Galvão (2008), a saber: 1) identificação do tema e seleção da questão de pesquisa para a elaboração da RIL; 2) estabelecimento de critérios para inclusão e exclusão de estudos e busca na literatura; 3) definição das informações a serem extraídas e categorização dos estudos; 4) avaliação dos estudos; 5) interpretação dos resultados; 6) síntese do conhecimento.

Esta revisão objetivou responder à seguinte questão: "O que se sabe sobre as experiências de EIP no contexto das RMS brasileiras?". Para tanto, foi realizado um levantamento bibliográfico, entre outubro e novembro de 2020, nas bases de dados contidas na Biblioteca Virtual de Saúde (BVS); Scopus, Medline e Biblioteca Digital Brasileira de Teses e Dissertações (BDTD); e, de modo complementar, no Google Acadêmico. Considerando a questão de pesquisa, elegeram-se os descritores, em português e inglês: internato não médico; educação de pós-graduação; relações interprofissionais; práticas interdisciplinares; práticas colaborativas; e termos não indexados relacionados ao tema: residência multiprofissional; residências em saúde; educação interprofissional; interprofissionalidade. A combinação dos termos foi realizada por meio dos operadores booleanos AND e OR.

Foram considerados os estudos publicados em português, inglês ou espanhol, que versassem sobre a EIP no âmbito das RMS no Brasil, e datados a partir de 2010, ano em que a OMS lançou o Marco para Ação em Educação Interprofissional e Prática Colaborativa, cuja finalidade foi sensibilizar os formuladores de políticas de saúde e educação para a importância da colaboração entre os profissionais. A seleção das publicações foi realizada conforme as seguintes etapas: 1) Triagem: quando foram excluídos os estudos repetidos, os publicados antes de 2010, os que abordavam assuntos não relacionados ao tema da revisão, e capítulos de livros, cartas, resumos e editoriais; 2) Elegibilidade: etapa em que os títulos e resumos foram lidos por duas revisoras independentes, aplicando-se os critérios previamente definidos; 3) Consenso: quando as publicações remanescentes foram recuperadas e submetidas à leitura integral pelas duas revisoras que, juntas, determinaram a inclusão ou exclusão do material selecionado.

A leitura das publicações foi orientada por um roteiro de análise estruturado em três blocos, composto por variáveis de interesse: (1) características de indexação das publicações: autoria, ano, idioma, título, fonte e tipo de publicação; (2) características de condução da pesquisa: objetivos e método (desenho, abordagem, cenário e amostragem); e (3) principais resultados relacionados ao tema. Por fim, os resultados emergidos foram tratados descritivamente quanto ao seu conteúdo.

\section{Resultados e Discussão}

As buscas resultaram em 379 publicações, sendo a maioria delas (32,7\%) listada na base virtual Medline. A Tabela 1 demonstra o quantitativo de publicações encontradas nas buscas antes da aplicação dos critérios de exclusão. 
Tabela 1. Total de publicações listadas nas bases de dados virtuais pesquisadas. Rio de Janeiro, RJ, 2020.

\begin{tabular}{lcc}
\hline Bases de dados & $\mathbf{n}$ & \% \\
\hline Medline & 124 & 32,7 \\
BVS & 102 & 26,9 \\
Scopus & 82 & 21,6 \\
BDTD & 41 & 10,8 \\
Google Acadêmico & 30 & 7,9 \\
\hline Total & $\mathbf{3 7 9}$ & $\mathbf{1 0 0}$ \\
\hline
\end{tabular}

Fonte: Dados da pesquisa.

Em seguida, foi realizado o refinamento de acordo com os critérios de exclusão, descartando-se 89,4\% das publicações. A amostra foi então composta por 37 estudos, conforme explicitado na Figura 1, que traz o fluxograma explicativo das etapas de seleção.

Figura 1. Fluxograma do processo de refinamento das publicações encontradas. Rio de Janeiro, RJ, 2020.

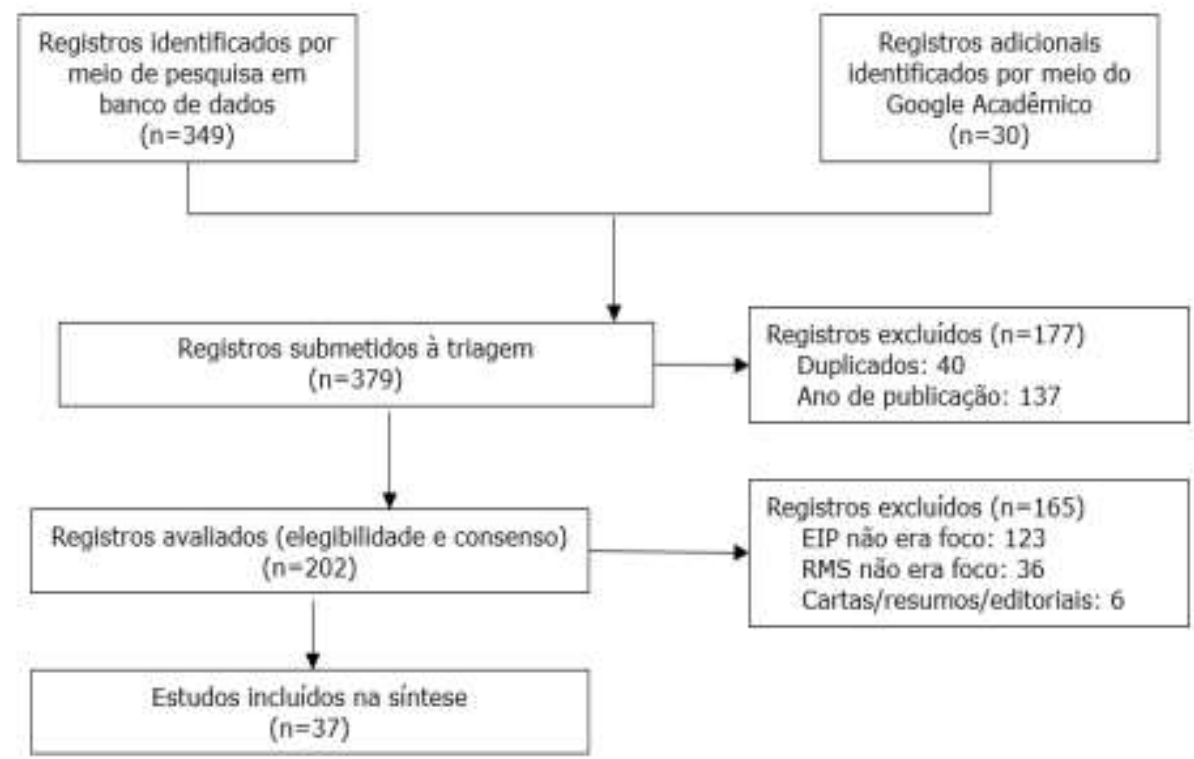

Fonte: Dados da pesquisa.

Como se observa no Quadro 1, foi encontrado um maior número de registros datados de 2018 ( $\mathrm{n}=12$ ), sob o formato de artigo $(n=24)$, publicados majoritariamente na Revista Interface (Botucatu) $(n=7)$, no idioma português ( $n=36)$. Insta mencionar que três artigos encontrados na busca derivaram de duas dissertações e uma tese, sendo todos eles incluídos para análise. Quanto ao método, a maioria dos estudos apresentou abordagem qualitativa $(\mathrm{n}=28)$, e caráter descritivo-exploratório $(n=14)$.

Ainda que a busca tenha considerado estudos publicados a partir do ano de 2010, os primeiros estudos encontrados sobre o tema datam de 2014. Infere-se que a concentração de estudos publicados em 2018 se deu devido a duas publicações lançadas pelo Ministério da Saúde no mesmo ano, incentivando o levantamento de iniciativas de EIP no Brasil e a produção de conhecimento e divulgação científica sobre o tema (Brasil, 2018a; 2018b).

Os estudos apresentaram, de acordo com seus objetivos (Quadro 2), três abordagens dentro do tema central da EIP nas RMS, quais sejam: (a) análise das percepções dos atores das RMS sobre princípios, práticas e concepções da EIP; (b) análise de instrumentos institucionais (projetos políticos pedagógicos - PPP) das RMS na perspectiva da EIP; e (c) experiências de implantação e desenvolvimento de atividades e práticas interprofissionais. 
A primeira abordagem traz reflexões sobre as potencialidades e limites das RMS como estratégia para o trabalho colaborativo a partir das vivências de residentes, preceptores, docentes e coordenadores. A segunda diz respeito à análise de documentos institucionais e organizacionais sob o olhar da EIP, neste caso, os PPP dos programas de RMS. Já a terceira abordagem corresponde aos relatos de experiências de EIP dentro dos programas de RMS, evidenciando práticas exitosas e desafios a serem superados.

A partir da interpretação dos achados dos 37 estudos incluídos, foram construídas três categorias que caracterizam a produção científica sobre a EIP no âmbito das RMS: "RMS como cenários para a promoção da EIP e das práticas colaborativas", "RMS e o desenvolvimento de competências para o trabalho interprofissional e transformação das práticas" e "Limites e desafios à EIP nas RMS" (Quadro 3). As análises serão apresentadas a seguir, permitindo a identificação dos elementos que contribuíram para a eleição destas categorias, bem como as devidas discussões. 
Research, Society and Development, v. 11, n. 2, e15711225510, 2022

(CC BY 4.0) | ISSN 2525-3409 | DOI: http://dx.doi.org/10.33448/rsd-v11i2.25510

Quadro 1. Características de indexação e aspectos metodológicos das publicações selecionadas para análise. Rio de Janeiro, RJ, 2020 (n=37).

\begin{tabular}{|c|c|c|c|c|}
\hline Autoria, ano & Título & Fonte & Desenho de estudo & Sujeitos e cenário \\
\hline Câmara AMCS, 2014 & $\begin{array}{l}\text { Oficina de educação interprofissional para a residência } \\
\text { multiprofissional }^{(1)}\end{array}$ & $\begin{array}{l}\text { Cadernos de Educação, } \\
\text { Saúde e Fisioterapia }\end{array}$ & $\begin{array}{l}\text { Relato de experiência } \\
\text { qualitativo }\end{array}$ & $\begin{array}{l}\text { Residentes de } 1^{\circ} \text { e } 2^{\circ} \text { ano/RMS Hospital das Clínicas da } \\
\text { Universidade Federal de Minas Gerais, Belo Horizonte }\end{array}$ \\
\hline $\begin{array}{l}\text { Motta LB, Pacheco } \\
\text { LC, } 2014\end{array}$ & $\begin{array}{l}\text { Integrating Medical and Health Multiprofessional Residency } \\
\text { Programs: The Experience in Building an Interprofessional } \\
\text { Curriculum for Health Professionals in Brazil }{ }^{(1)}\end{array}$ & Education for Health & $\begin{array}{l}\text { Relato de experiência } \\
\text { qualitativo }\end{array}$ & $\begin{array}{l}\text { Residentes } \quad(\mathrm{n}=26) \text { e preceptores } \quad(\mathrm{n}=25) \text { de diferentes } \\
\text { áreas/Residência Médica em Geriatria, RMS em Saúde do } \\
\text { Idoso/UERJ, Rio de Janeiro }\end{array}$ \\
\hline $\begin{array}{l}\text { Casanova IA et al., } \\
2015\end{array}$ & $\begin{array}{l}\text { Formação para o trabalho em equipe na residência } \\
\text { multiprofissional em saúde }{ }^{(1)}\end{array}$ & ABCS Health Sciences & $\begin{array}{c}\text { Descritivo-exploratório } \\
\text { qualitativo }\end{array}$ & $\begin{array}{l}\text { Residentes do } 2^{\circ} \text { ano (n=76) /Duas instituições públicas } \\
\text { (federal e estadual), estado de São Paulo }\end{array}$ \\
\hline $\begin{array}{l}\text { Casanova IA et al., } \\
2015\end{array}$ & $\begin{array}{l}\text { Residência Multiprofissional em Saúde: percepção dos } \\
\text { residentes sobre a Educação Interprofissional nas práticas } \\
\text { colaborativas }^{(1)}\end{array}$ & $\begin{array}{l}\text { Atas do Congresso Ibero- } \\
\qquad \text { Americano em } \\
\text { Investigação Qualitativa }\end{array}$ & $\begin{array}{l}\text { Descritivo-exploratório } \\
\text { qualitativo }\end{array}$ & Residentes do $1^{\circ}$ ano ( $\mathrm{n}=9$ )/Instituição filantrópica, São Paulo \\
\hline $\begin{array}{l}\text { Miranda Neto MV et } \\
\text { al., } 2015\end{array}$ & $\begin{array}{l}\text { Residências multiprofissionais em saúde: análise } \\
\text { documental de projetos político-pedagógicos }{ }^{(1)}\end{array}$ & $\begin{array}{l}\text { Revista Brasileira de } \\
\text { Enfermagem }\end{array}$ & $\begin{array}{l}\text { Descritivo-exploratório } \\
\text { qualitativo }\end{array}$ & $\begin{array}{l}\text { PPP de seis programas de RMS com ênfase em Atenção Básica } \\
\text { ou em área de concentração em Saúde da Família ou Saúde } \\
\text { Coletiva do estado de São Paulo }\end{array}$ \\
\hline $\begin{array}{l}\text { Miranda Neto MV, } \\
2015\end{array}$ & $\begin{array}{l}\text { Limites e potencialidades da residência multiprofissional em } \\
\text { saúde para a educação interprofissional }^{(2)}\end{array}$ & Universidade de São Paulo & $\begin{array}{l}\text { Descritivo-exploratório } \\
\text { qualitativo }\end{array}$ & $\begin{array}{l}\text { PPP de seis programas de RMS com ênfase em Atenção Básica } \\
\text { ou em área de concentração em Saúde da Família ou Saúde } \\
\text { Coletiva/Residentes matriculados no programa selecionado } \\
\text { como cenário mais favorável à EIP/Estado de São Paulo }\end{array}$ \\
\hline Soares GMM, 2015 & $\begin{array}{l}\text { Colaboração e educação interprofissional na pós-graduação } \\
\text { em saúde: estudo de caso da residência multiprofissional em } \\
\text { saúde da família }{ }^{(2)}\end{array}$ & $\begin{array}{l}\text { Universidade Federal do } \\
\text { Ceará }\end{array}$ & $\begin{array}{l}\text { Relato de experiência } \\
\text { qualitativo }\end{array}$ & $\begin{array}{l}\text { Coordenadores, preceptores e residentes }(\mathrm{n}=24) / \text { Residência } \\
\text { Integrada em Saúde da Escola de Saúde Pública do } \\
\text { Ceará/Municípios de Maracanaú e Aracati, Ceará. }\end{array}$ \\
\hline Santos KH et al., 2016 & $\begin{array}{l}\text { O trabalho de profissionais na residência multiprofissional } \\
\text { em saúde }{ }^{(1)}\end{array}$ & Revista de APS & $\begin{array}{l}\text { Relato de experiência } \\
\text { qualitativo }\end{array}$ & $\begin{array}{llll}\text { Três } \quad \text { residentes } \quad \text { enfermeira, } & \text { fonoaudióloga } & \text { e } \\
\text { nutricionista)/Programa } & \text { de Residência } & \text { Multiprofissional da } \\
\text { Universidade Estadual de Campinas, São } & \text { Paulo. }\end{array}$ \\
\hline $\begin{array}{l}\text { Perego MG, Batista } \\
\text { NA, } 2016\end{array}$ & \begin{tabular}{|llll} 
Aprendizagens Compartilhadas & na & Residência \\
Multiprofissional em Saúde & $(1)$ & & \\
\end{tabular} & Tempus & $\begin{array}{l}\text { Descritivo-exploratório, } \\
\text { transversal, e quantitativo }\end{array}$ & $\begin{array}{l}\text { Residentes egressos, preceptores e tutores do Programa de } \\
\text { Residência Multiprofissional em Atenção à Saúde de do }\end{array}$ \\
\hline
\end{tabular}


Research, Society and Development, v. 11, n. 2, e15711225510, 2022

(CC BY 4.0) | ISSN 2525-3409 | DOI: http://dx.doi.org/10.33448/rsd-v11i2.25510

\begin{tabular}{|c|c|c|c|c|}
\hline & & & & Campus Baixada Santista, São Paulo. \\
\hline $\begin{array}{l}\text { Frossard AGS, Silva } \\
\text { ECS, } 2016\end{array}$ & $\begin{array}{l}\text { Experiência da residência multiprofissional em serviço } \\
\text { social e cuidados paliativos oncológicos }{ }^{(1)}\end{array}$ & Revista Katálysis & $\begin{array}{c}\text { Relato de experiência, } \\
\text { descritivo-exploratório, e } \\
\text { qualitativo }\end{array}$ & $\begin{array}{l}\text { Residência multiprofissional em Serviço Social e cuidados } \\
\text { paliativos oncológicos, Ceará. }\end{array}$ \\
\hline $\begin{array}{l}\text { Dias IMAV et al., } \\
2016\end{array}$ & $\begin{array}{l}\text { A tutoria no processo de ensino-aprendizagem no contexto } \\
\text { da formação interprofissional em saúde }{ }^{(1)}\end{array}$ & Saúde em Debate & Estudo de caso qualitativo & Tutores de um programa de RMS, Rio de Janeiro. \\
\hline $\begin{array}{l}\text { Arruda GMMS et al., } \\
\qquad 2016\end{array}$ & $\begin{array}{l}\text { Educação interprofissional na pós-graduação em saúde: } \\
\text { dimensões pedagógicas interprofissionais em uma } \\
\text { Residência Multiprofissional em Saúde da Família }{ }^{(1)}\end{array}$ & Tempus & Estudo de caso qualitativo & $\begin{array}{l}2 \text { coordenadores, } 7 \text { preceptores e } 15 \text { residentes/ Programa de } \\
\text { Residência Multiprofissional em Saúde da Família e } \\
\text { Comunidade da Escola de Saúde Pública do Ceará. }\end{array}$ \\
\hline Medina AG, 2016 & $\begin{array}{l}\text { Terapia ocupacional } \text { e a educação para a } \\
\text { interprofissionalidade em residências multiprofissionais em } \\
\text { saúde } \\
\text { saú }^{(2)}\end{array}$ & Universidade de São Paulo & $\begin{array}{l}\text { Descritivo-exploratório } \\
\text { qualitativo }\end{array}$ & $\begin{array}{l}\text { Tutores, preceptores e residentes terapeutas ocupacionais } \\
(\mathrm{n}=17) / \text { Três programas de RMS, São Paulo. }\end{array}$ \\
\hline $\begin{array}{l}\text { Araújo TAM et al., } \\
\qquad 2017\end{array}$ & $\begin{array}{l}\text { Multiprofissionalidade e interprofissionalidade em uma } \\
\text { residência hospitalar: o olhar de residentes e preceptores }{ }^{(1)}\end{array}$ & $\begin{array}{l}\text { Interface, Comunicação, } \\
\text { Saúde, Educação }\end{array}$ & Exploratório qualitativo & $\begin{array}{l}\text { Residentes do segundo ano e preceptores/Residência Integrada } \\
\text { Multiprofissional em Saúde Hospitalar (Atenção à Saúde da } \\
\text { Criança e do Adolescente; Atenção à Saúde do Idoso; e } \\
\text { Atenção ao Paciente Crítico), Nordeste. }\end{array}$ \\
\hline Brito JSS, 2017 & $\begin{array}{l}\text { Análise da educação interprofissional em saúde através da } \\
\text { experiência da residência multiprofissional em saúde da } \\
\text { família }^{(2)}\end{array}$ & Fundação Oswaldo Cruz & $\begin{array}{l}\text { Descritivo-exploratório } \\
\text { qualitativo }\end{array}$ & $\begin{array}{l}\text { Docentes, preceptores e residentes que tivessem cursado o } \\
\text { primeiro ano do curso/Dois programas de Residência } \\
\text { Multiprofissional em Saúde da Família, Pernambuco. }\end{array}$ \\
\hline Silva AS, 2017 & $\begin{array}{l}\text { Percepção de residentes e preceptores sobre a residência } \\
\text { multiprofissional integrada em saúde com ênfase em onco- } \\
\text { hematologia }^{(2)}\end{array}$ & $\begin{array}{l}\text { Universidade Federal de } \\
\text { Ciências da Saúde de Porto } \\
\text { Alegre }\end{array}$ & $\begin{array}{l}\text { Estudo transversal, } \\
\text { qualitativo e quantitativo }\end{array}$ & $\begin{array}{l}\text { Residentes de } 1^{\circ} \text { e } 2^{\circ} \text { ano e preceptores do Programa RMS com } \\
\text { ênfase em onco-hematologia/Hospital Santa Rita, Porto } \\
\text { Alegre. }\end{array}$ \\
\hline $\begin{array}{l}\text { Arruda GMMS et al., } \\
\qquad 2018\end{array}$ & $\begin{array}{l}\text { O desenvolvimento da colaboração interprofissional em } \\
\text { diferentes contextos de residência multiprofissional em } \\
\text { Saúde da Família }{ }^{(1)}\end{array}$ & $\begin{array}{l}\text { Interface, Comunicação, } \\
\text { Saúde, Educação }\end{array}$ & Estudo de casos múltiplos & $\begin{array}{l}\text { Coordenadores, preceptores e residentes }(\mathrm{n}=24) / \text { Residência } \\
\text { multiprofissional em Saúde da Família/ Maracanaú e Aracati, } \\
\text { Ceará. }\end{array}$ \\
\hline Aguiar RBPL, 2018 & $\begin{array}{l}\text { Interdisciplinaridade e prática colaborativa na percepção dos } \\
\text { preceptores de um programa de residência multiprofissional } \\
\text { em neurologia e neurocirurgia }{ }^{(2)}\end{array}$ & $\begin{array}{l}\text { Centro Universitário } \\
\text { Christus }\end{array}$ & $\begin{array}{l}\text { Descritivo-exploratório, } \\
\text { qualitativo e quantitativo }\end{array}$ & Preceptores (n=34)/Hospital Geral de Fortaleza (HGF), Ceará. \\
\hline
\end{tabular}


Research, Society and Development, v. 11, n. 2, e15711225510, 2022

(CC BY 4.0) | ISSN 2525-3409 | DOI: http://dx.doi.org/10.33448/rsd-v11i2.25510

\begin{tabular}{|c|c|c|c|c|}
\hline $\begin{array}{l}\text { Casanova IA et al., } \\
2018\end{array}$ & $\begin{array}{l}\text { A Educação Interprofissional e a prática compartilhada em } \\
\text { programas de residência multiprofissional em Saúde }{ }^{(1)}\end{array}$ & $\begin{array}{l}\text { Interface, Comunicação, } \\
\text { Saúde, Educação }\end{array}$ & $\begin{array}{l}\text { Descritivo-exploratório, } \\
\text { qualitativo e quantitativo }\end{array}$ & $\begin{array}{l}\text { Residentes do } 2^{\circ} \text { ano }(n=76) / \text { Treze programas de RMS, Estado } \\
\text { de São Paulo. }\end{array}$ \\
\hline $\begin{array}{l}\text { Albuquerque ERN et } \\
\text { al., } 2018\end{array}$ & $\begin{array}{l}\text { Residências multiprofissionais em saúde como } \\
\text { fomentadoras da formação interprofissional: percepção de } \\
\text { nutricionistas sobre as práticas colaborativas }{ }^{(1)}\end{array}$ & Demetra & $\begin{array}{l}\text { Descritivo-exploratório, } \\
\text { quantitativo }\end{array}$ & Residentes de $2^{\circ}$ ano de RMS/Nove estados do Nordeste. \\
\hline $\begin{array}{l}\text { Arnemann CT et al., } \\
2018\end{array}$ & $\begin{array}{l}\text { Práticas exitosas dos preceptores de uma residência } \\
\text { multiprofissional: interface com a interprofissionalidade }{ }^{(1)}\end{array}$ & $\begin{array}{l}\text { Interface, Comunicação, } \\
\text { Saúde, Educação }\end{array}$ & $\begin{array}{l}\text { Pesquisa apreciativa } \\
\text { qualitativa }\end{array}$ & Preceptores ( $n=7) /$ Hospital de Clínicas de Porto Alegre. \\
\hline $\begin{array}{l}\text { Camargo FC et al., } \\
\qquad 2018\end{array}$ & $\begin{array}{l}\text { Formação para o trabalho na estratégia saúde da família: } \\
\text { experiência da residência multiprofissional em saúde }{ }^{(1)}\end{array}$ & $\begin{array}{l}\text { Revista de Enfermagem e } \\
\text { Atenção à Saúde }\end{array}$ & $\begin{array}{l}\text { Relato de experiência } \\
\text { qualitativo }\end{array}$ & $\begin{array}{l}\text { Residência Integrada Multiprofissional em Saúde do Hospital } \\
\text { de Clínicas da Universidade Federal do Triângulo Mineiro, } \\
\text { MG. }\end{array}$ \\
\hline $\begin{array}{l}\text { Evangelista ALP et } \\
\text { al., } 2018\end{array}$ & $\begin{array}{l}\text { Residência integrada em saúde mental: cuidado à Rede de } \\
\text { Atenção Psicossocial }^{(1)}\end{array}$ & $\begin{array}{l}\text { Revista Brasileira em } \\
\text { Promoção da Saúde }\end{array}$ & $\begin{array}{l}\text { Descritivo-exploratório } \\
\text { qualitativo }\end{array}$ & $\begin{array}{l}\text { Secretários municipais de saúde }(n=4) \text {, Coordenadores de } \\
\text { Saúde Mental }(n=3) \text {, Articuladores }(n=3) \text {, Gerentes }(n=3) \text { e } \\
\text { profissionais dos CAPS ( } n=3) \text {, Preceptores }(n=3) \text {, Residentes } \\
(n=15) / \text { Residência Integrada em Saúde Mental Coletiva da } \\
\text { Escola de Saúde Pública, quatro municípios do Ceará. }\end{array}$ \\
\hline Costa BF, 2018 & $\begin{array}{l}\text { A atenção básica como cenário de implementação da } \\
\text { educação interprofissional em saúde: na perspectiva dos } \\
\text { residentes }^{(2)}\end{array}$ & $\begin{array}{l}\text { Universidade Federal do } \\
\text { Rio Grande do Norte }\end{array}$ & Pesquisa-ação qualitativa & $\begin{array}{l}\text { Residentes de } 1^{\circ} \text { ano }(\mathrm{n}=9) \text { e } 2^{\circ} \text { ano }(\mathrm{n}=7) \text { do Programa de } \\
\text { Residência Multiprofissional em Atenção Básica e um } \\
\text { residente de } 1^{\circ} \text { ano da Residência em Medicina de Família e } \\
\text { Comunidade da Escola Multicampi de Ciências Médicas da } \\
\text { Universidade Federal do Rio Grande do Norte/Município de } \\
\text { Caicó/RN }\end{array}$ \\
\hline Lago LPM et al., 2018 & $\begin{array}{l}\text { A análise de práticas profissionais como dispositivo para a } \\
\text { formação na residência multiprofissional }^{(1)}\end{array}$ & $\begin{array}{l}\text { Interface, Comunicação, } \\
\text { Saúde, Educação }\end{array}$ & $\begin{array}{l}\text { Pesquisa-intervenção } \\
\text { qualitativa }\end{array}$ & $\begin{array}{l}\text { Residentes de } 1^{\circ} \text { e } 2^{\circ} \text { ano }(n=32) \text { de uma universidade pública } \\
\text { do interior do estado de São Paulo. }\end{array}$ \\
\hline Leitão BFB, 2018 & $\begin{array}{l}\text { Residência multiprofissional em cancerologia: expressões da } \\
\text { integralidade do cuidado }^{(2)}\end{array}$ & $\begin{array}{l}\text { Universidade Federal do } \\
\text { Ceará }\end{array}$ & Abordagem qualitativa & $\begin{array}{l}\text { Residentes egressos ( } \mathrm{n}=30) \text { do Programa de Residência } \\
\text { Integrada em Saúde com ênfase em Cancerologia da Escola de } \\
\text { Saúde Pública do Ceará e do Instituto do Câncer do Ceará. }\end{array}$ \\
\hline $\begin{array}{l}\text { Medeiros MSMF, } \\
2018\end{array}$ & $\begin{array}{l}\text { Educação para o trabalho interprofissional no contexto das } \\
\text { residências em uma maternidade escola } \\
(2)\end{array}$ & $\begin{array}{l}\text { Universidade Federal do } \\
\text { Rio Grande do Norte }\end{array}$ & $\begin{array}{l}\text { Estudo de caso, descritivo- } \\
\text { exploratório, e qualitativo }\end{array}$ & $\begin{array}{l}\text { Alunos da residência médica }(\mathrm{n}=6) \text { e multiprofissional }(\mathrm{n}=14) \\
\text { de uma maternidade escola da Universidade Federal do Rio }\end{array}$ \\
\hline
\end{tabular}


Research, Society and Development, v. 11, n. 2, e15711225510, 2022

(CC BY 4.0) | ISSN 2525-3409 | DOI: http://dx.doi.org/10.33448/rsd-v11i2.25510

\begin{tabular}{|c|c|c|c|c|}
\hline & & & & Grande do Norte. \\
\hline Wetzel C et al., 2018 & $\begin{array}{l}\text { Análise sobre a formação interprofissional em serviço em } \\
\text { um Centro de Atenção Psicossocial }{ }^{(1)}\end{array}$ & $\begin{array}{l}\text { Interface, Comunicação, } \\
\text { Saúde, Educação }\end{array}$ & $\begin{array}{l}\text { Abordagens qualitativa e } \\
\text { quantitativa }\end{array}$ & $\begin{array}{l}\text { Usuários, familiares, trabalhadores do Caps-AD e } \\
\text { gestores/Município do estado do Rio Grande do Sul. }\end{array}$ \\
\hline Lago LPM, 2019 & $\begin{array}{l}\text { Práticas profissionais na residência multiprofissional em } \\
\text { saúde: uma pesquisa Sócio-clínica }{ }^{(3)}\end{array}$ & Universidade de São Paulo & $\begin{array}{l}\text { Pesquisa-intervenção } \\
\text { qualitativa }\end{array}$ & $\begin{array}{l}\text { Residentes }(\mathrm{n}=32) \text { e docentes e ex-docentes }(\mathrm{n}=8) \text { do Programa } \\
\text { de Residência Multiprofissional em Atenção Integral à Saúde } \\
\text { da Faculdade de Medicina de Ribeirão Preto da Universidade } \\
\text { de São Paulo. }\end{array}$ \\
\hline Alves IMF, 2019 & $\begin{array}{l}\text { A colaboração interprofissional em um programa de } \\
\text { residência multiprofissional em saúde: um relato de } \\
\text { experiência }^{(4)}\end{array}$ & $\begin{array}{l}\text { Universidade Federal do } \\
\text { Rio Grande do Norte }\end{array}$ & $\begin{array}{l}\text { Relato de experiência } \\
\text { qualitativo }\end{array}$ & $\begin{array}{l}\text { Residente enfermeira do } 1^{\circ} \text { ano em uma Unidade Básica de } \\
\text { Saúde localizada no município de Caicó, Rio Grande do Norte. }\end{array}$ \\
\hline $\begin{array}{l}\text { Henrique RS et al., } \\
\qquad 2019\end{array}$ & $\begin{array}{l}\text { Múltiplos olhares: a busca pela interprofissionalidade em } \\
\text { uma equipe de residentes multiprofissionais em saúde da } \\
\text { família no município do Rio de Janeiro (RJ) }{ }^{(1)}\end{array}$ & $\begin{array}{l}\text { Anais do } 16^{\circ} \text { Congresso } \\
\text { Brasileiro de Assistentes } \\
\text { Sociais }\end{array}$ & Relato de experiência & $\begin{array}{l}\text { Residentes multiprofissionais em Saúde da } \\
\text { Família/Jacarezinho, Rio de Janeiro. }\end{array}$ \\
\hline $\begin{array}{l}\text { Lewgoy AMB et al., } \\
\qquad 2019\end{array}$ & $\begin{array}{l}\text { A perspectiva interprofissional na residência integrada } \\
\text { multiprofissional em saúde hospitalar }\end{array}$ & $\begin{array}{l}\text { Clinical \& Biomedical } \\
\text { Research }\end{array}$ & Relato de experiência & $\begin{array}{l}\text { Residentes do } 1^{\circ} \text { ano da RMS na ênfase de Controle de } \\
\text { Infecção Hospitalar/Universidade Federal do Rio Grande do } \\
\text { Sul, Hospital de Clínicas de Porto Alegre. }\end{array}$ \\
\hline $\begin{array}{l}\text { Lima ICBF, Passos } \\
\text { ICF, } 2019\end{array}$ & $\begin{array}{l}\text { Residências integradas em saúde mental: para além do } \\
\text { tecnicismo }^{(1)}\end{array}$ & Trabalho, Educação, Saúde & Abordagem qualitativa & $\begin{array}{l}\text { PPP e profissionais envolvidos na coordenação e na } \\
\text { preceptoria }(\mathrm{n}=3) \text { do Programa de Residências Integradas em } \\
\text { Saúde Mental do Hospital Odilon Behrens, da Prefeitura } \\
\text { Municipal de Belo Horizonte, MG. }\end{array}$ \\
\hline $\begin{array}{l}\text { Rebouças RRM et al., } \\
\qquad 2019\end{array}$ & $\begin{array}{l}\text { (Im)Possibilidades de atuação interprofissional dos } \\
\text { residentes multiprofissionais em contexto hospitalar }{ }^{(1)}\end{array}$ & Revista da SBPH & $\begin{array}{c}\text { Pesquisa participante, } \\
\text { exploratória, e qualitativa }\end{array}$ & $\begin{array}{l}\text { Residentes de } 1^{\circ} \text { e } 2^{\circ} \text { ano }(\mathrm{n}=6) \text { da ênfase Cardiopulmonar, do } \\
\text { Hospital Dr. Carlos Alberto Studart Gomes }- \text { Hospital de } \\
\text { Messejana, Fortaleza, Ceará. }\end{array}$ \\
\hline Sanches MV, 2019 & $\begin{array}{l}\text { A experiência do programa de residência multiprofissional } \\
\text { em saúde mental com ênfase em dependência química: } \\
\text { desafios para a educação interprofissional colaborativa }{ }^{(2)}\end{array}$ & Universidade de São Paulo & $\begin{array}{l}\text { Descritivo-exploratório e } \\
\text { qualitativo }\end{array}$ & $\begin{array}{l}\text { PPP. Egressos, residentes, docentes, preceptores e coordenação } \\
\text { (n=23) do programa de RMS em Saúde Mental com ênfase em } \\
\text { dependência química da Faculdade de Medicina da } \\
\text { Universidade de São Paulo. }\end{array}$ \\
\hline Dantas BT, 2020 & Estratégias de ensino-avaliação voltadas ao desenvolvimento & Universidade Federal do & Quase-experimental & Residentes (n=59) da Residência Multiprofissional em Saúde, \\
\hline
\end{tabular}


Research, Society and Development, v. 11, n. 2, e15711225510, 2022

(CC BY 4.0) | ISSN 2525-3409 | DOI: http://dx.doi.org/10.33448/rsd-v11i2.25510

\begin{tabular}{|c|c|c|c|c|}
\hline & $\begin{array}{l}\text { de competências para o trabalho em equipe na residência } \\
\text { multiprofissional em saúde }{ }^{(2)}\end{array}$ & Rio Grande do Norte & quantitativo & $\begin{array}{l}\text { do Hospital Universitário Onofre Lopes, Universidade Federal } \\
\text { do Rio Grande do Norte. }\end{array}$ \\
\hline $\begin{array}{l}\text { Querido DL et al., } \\
\qquad 2020\end{array}$ & $\begin{array}{l}\text { Residência multiprofissional como estratégia para formação } \\
\text { de recursos humanos na perspectiva interprofissional em } \\
\text { saúde perinatal }^{(1)}\end{array}$ & $\begin{array}{l}\text { Research, Society and } \\
\text { Development }\end{array}$ & Exploratório e qualitativo & $\begin{array}{l}\text { Egressos }(\mathrm{n}=18) \text { e preceptores }(\mathrm{n}=17) \text { do Programa de } \\
\text { Residência Multiprofissional em Saúde Perinatal da } \\
\text { Maternidade Escola da Universidade Federal do Rio de } \\
\text { Janeiro. }\end{array}$ \\
\hline
\end{tabular}

1) Artigo; (2) Dissertação; ${ }^{(3)}$ Tese; ${ }^{(4)}$ Trabalho de conclusão de residência. Fonte: Dados da pesquisa. ( 
Quadro 2. Objetivos e principais resultados das publicações selecionadas para análise. Rio de Janeiro, RJ, 2020 (n=37).

\begin{tabular}{|c|c|c|}
\hline Autor, ano & Objetivo & Resultados \\
\hline Câmara AMCS, 2014 & $\begin{array}{l}\text { Relatar a experiência de uma oficina de educação interprofissional } \\
\text { para o Programa de RMS do Hospital das Clínicas da UFMG a } \\
\text { fim de melhorar o aprendizado interprofissional e promover uma } \\
\text { perspectiva multidimensional do cuidado centrado no indivíduo. }\end{array}$ & $\begin{array}{l}\text { A oficina instrumentalizou os residentes para a prática colaborativa centrada no indivíduo. Introduziu a } \\
\text { Classificação Internacional de Funcionalidade e o mapa conceitual como ferramentas fundamentais para a } \\
\text { elaboração de projetos terapêuticos compartilhados, aproximou olhares e facilitou a comunicação entre os } \\
\text { profissionais. A oficina foi uma estratégia importante na formação dos novos residentes da RMS para o } \\
\text { desenvolvimento de competências para o trabalho interprofissional. }\end{array}$ \\
\hline $\begin{array}{l}\text { Motta LB, Pacheco } \\
\text { LC, } 2014\end{array}$ & $\begin{array}{l}\text { Descrever a criação de um programa de treinamento } \\
\text { interprofissional integrando as residências médica e } \\
\text { multiprofissional. }\end{array}$ & $\begin{array}{l}\text { O treinamento ocorreu em seis cenários de prática distribuídos ao longo de dois anos. Atividades interprofissionais } \\
\text { foram organizadas por preceptores e foram avaliadas positivamente. Programas de residência são boas } \\
\text { oportunidades para o desenvolvimento de treinamento interprofissional para práticas colaborativas centradas no } \\
\text { paciente. }\end{array}$ \\
\hline $\begin{array}{l}\text { Casanova IA et al., } \\
2015\end{array}$ & $\begin{array}{l}\text { Analisar a percepção dos profissionais que cursam a RMS sobre a } \\
\text { formação para o trabalho em equipe. }\end{array}$ & $\begin{array}{l}\text { Foi identificado o potencial da RMS em formar profissionais de saúde para o trabalho em equipe e, } \\
\text { consequentemente, para a transformação das práticas, com vistas à integralidade no cuidado. }\end{array}$ \\
\hline $\begin{array}{l}\text { Casanova IA et al., } \\
2015\end{array}$ & $\begin{array}{l}\text { Analisar a percepção de residentes da RMS sobre as práticas } \\
\text { colaborativas. }\end{array}$ & $\begin{array}{l}\text { Os residentes concordam que a residência proporciona uma formação para a prática colaborativa entre os } \\
\text { profissionais potencializada por um perfil de quem procura a residência e o desenvolvimento de competências } \\
\text { comuns e específicas fortalecendo as ações de saúde centrada no usuário. }\end{array}$ \\
\hline $\begin{array}{l}\text { Miranda Neto MV et } \\
\text { al., } 2015\end{array}$ & $\begin{array}{l}\text { Analisar os PPP de programas de RMS do estado de São Paulo e } \\
\text { identificar os cenários altamente favoráveis à EIP. }\end{array}$ & $\begin{array}{l}\text { A análise documental revelou um cenário heterogêneo no que diz respeito a currículos, organização didático- } \\
\text { pedagógica, objetivos educacionais, matrizes pedagógicas e sistemas de avaliação utilizados. Um dos programas foi } \\
\text { identificado como um cenário altamente favorável à EIP. }\end{array}$ \\
\hline $\begin{array}{l}\text { Miranda Neto MV, } \\
2015\end{array}$ & $\begin{array}{l}\text { Compreender limites e potencialidades das RMS para a EIP, } \\
\text { descrever os programas de RMS do estado de São Paulo, } \\
\text { identificar um programa com o cenário mais favorável à EIP e } \\
\text { analisar a percepção dos residentes a respeito dos limites e } \\
\text { potencialidades desta RMS. }\end{array}$ & $\begin{array}{l}\text { A análise documental revelou um programa com cenário altamente favorável para a EIP. Como limites importantes } \\
\text { à EIP foram identificados a rigidez curricular, cronogramas inadequados e conteúdos insuficientes. Os residentes } \\
\text { reiteraram que a residência contribuiu para fortalecer a identidade profissional, assim como para o reconhecimento } \\
\text { de competências comuns. }\end{array}$ \\
\hline Soares GMM, 2015 & $\begin{array}{l}\text { Analisar o processo de implementação da educação } \\
\text { interprofissional e da prática colaborativa no cotidiano da } \\
\text { residência em Saúde da Família e Comunidade. }\end{array}$ & $\begin{array}{l}\text { A residência estudada se organiza como estratégia de EIP devido aos seguintes aspectos identificados: currículo } \\
\text { baseado em competências. educação pelo trabalho, lotação dos residentes em equipes multiprofissionais. No } \\
\text { processo ensino-aprendizagem identificou-se a potência da metodologia da tenda invertida, do dispositivo de roda e } \\
\text { do papel do preceptor. Percebeu-se um isolamento dos residentes no segundo ano. }\end{array}$ \\
\hline Santos KH et al., 2016 & $\begin{array}{l}\text { Conhecer a atuação interprofissional de residentes em saúde } \\
\text { durante atendimentos de puericultura de uma criança com paralisia } \\
\text { cerebral. }\end{array}$ & $\begin{array}{l}\text { Construção de um projeto terapêutico singular a partir de atendimento interprofissional. As ações compartilhadas e } \\
\text { interativas entre os três núcleos profissionais promoveram um trabalho cujo foco centrou-se nas necessidades de } \\
\text { saúde dos usuários, possibilitando intervenções que abrangeram a criança e seu núcleo familiar. }\end{array}$ \\
\hline $\begin{array}{l}\text { Perego MG, Batista } \\
\quad \text { NA, } 2016\end{array}$ & $\begin{array}{l}\text { Investigar a percepção de residentes, preceptores e tutores da RMS } \\
\text { sobre as aprendizagens compartilhadas na formação para o } \\
\text { trabalho em equipe de profissionais da saúde, através de uma } \\
\text { escala atitudinal validada. }\end{array}$ & $\begin{array}{l}\text { Não houve diferenças significativas entre as profissões sobre a aprendizagem compartilhada na RMS, sendo a pior } \\
\text { percepção dos enfermeiros e a melhor de fisioterapeutas e nutricionistas. A média das asserções da escala atitudinal } \\
\text { foi de } 3,20 \text {, classificadas em zona de conforto. }\end{array}$ \\
\hline
\end{tabular}


Research, Society and Development, v. 11, n. 2, e15711225510, 2022

\begin{tabular}{|c|c|c|}
\hline ECS, 2016 & $\begin{array}{l}\text { Cuidados Paliativos do Instituto do Câncer do Ceará, descrevendo } \\
\text { como se deu a conformação entre as estratégias de intervenção } \\
\text { profissional nos cuidados paliativos oncológicos com a residência. }\end{array}$ & $\begin{array}{l}\text { qualificada do familiar ou cuidador, orientação quanto à normas e serviços disponibilizados pelo programa. Usou-se } \\
\text { uma abordagem interdisciplinar para acessar necessidades clínicas e psicossociais dos pacientes e suas famílias, } \\
\text { incluindo aconselhamento e suporte ao luto. Realizou-se também o estudo de caso interprofissional semanalmente e } \\
\text { a construção do projeto terapêutico adequado à singularidade de cada caso. Desafios identificados: excessiva carga } \\
\text { horária, número insuficiente de profissionais para supervisão dos residentes, deficiências na rede de saúde e } \\
\text { serviços, atual contexto político das residências multiprofissionais e dificuldades de consolidação de um espaço } \\
\text { democrático de discussão entre os residentes, coordenadores e gestores do Programa. A concepção pedagógica } \\
\text { pautou-se na educação permanente como princípio pedagógico e metodológico. }\end{array}$ \\
\hline $\begin{array}{l}\text { Dias IMAV et al., } \\
2016\end{array}$ & $\begin{array}{l}\text { Analisar a configuração de um Programa de Residência } \\
\text { Multiprofissional em Saúde, na perspectiva dos tutores, versando } \\
\text { sobre o processo de ensino-aprendizado no contexto da formação } \\
\text { interdisciplinar, que corresponde ao universo de disciplinas } \\
\text { teóricas, e interprofissional, concernente às questões práticas da } \\
\text { profissão. }\end{array}$ & $\begin{array}{l}\text { Observa-se, na fala dos tutores, a importância da vivência do trabalho interprofissional, colocada como fator } \\
\text { determinante no aprendizado desse novo modelo. Os tutores não apresentam segurança em definir conceitualmente } \\
\text { a interprofissionalidade. A vivência resultou em um crescimento significativo, que permitiu a contemplação de } \\
\text { novos horizontes. }\end{array}$ \\
\hline $\begin{array}{l}\text { Arruda GMMS et al., } \\
\qquad 2016\end{array}$ & Analisa a proposta pedagógica da RMS na perspectiva da EIP. & $\begin{array}{l}\text { Observou-se que a RMS se organiza como estratégia de EIP por vários aspectos: currículo baseado em } \\
\text { competências, educação pelo trabalho, lotação dos residentes em equipes multiprofissionais, formação de adultos, } \\
\text { dentre outros. No processo de ensino-aprendizagem, capturou-se a potência da metodologia da tenda invertida, do } \\
\text { método da roda e do papel do preceptor de campo no estímulo e apoio ao trabalho e à aprendizagem } \\
\text { interprofissional. Dentre os desafios, encontram-se o processo de interiorização da educação permanente, a } \\
\text { sustentabilidade financeira do PRMSFC e a dependência do processo formativo à adesão dos atores envolvidos. }\end{array}$ \\
\hline Medina AG, 2016 & $\begin{array}{l}\text { Conhecer e refletir sobre os desafios e tendências do processo de } \\
\text { educação profissional e interprofissional na perspectiva de tutores, } \\
\text { preceptores e residentes terapeutas ocupacionais. }\end{array}$ & $\begin{array}{l}\text { O processo formativo foi impactado pela contratação insuficiente de profissionais nos serviços, pelo } \\
\text { desconhecimento do papel profissional do terapeuta ocupacional e pela fragmentação da atuação profissional nos } \\
\text { cenários de prática. A importância das RMS no aprendizado de saberes e práticas próprios da profissão, comuns e } \\
\text { colaborativos foi reconhecida pelos participantes. }\end{array}$ \\
\hline $\begin{array}{c}\text { Araújo TAM et al., } \\
2017\end{array}$ & $\begin{array}{l}\text { Refletir sobre a percepção de residentes e preceptores quanto ao } \\
\text { trabalho multiprofissional e interprofissional, a partir de uma } \\
\text { experiência de Residência Multiprofissional em Saúde Hospitalar, } \\
\text { em uma capital do Nordeste do Brasil. }\end{array}$ & $\begin{array}{l}\text { Fragilidade dos conceitos sobre multiprofissionalidade e interprofissionalidade; confusão e dualidade quanto ao } \\
\text { (re)conhecimento do papel dos residentes nos cenários de prática. A residência foi capaz de trazer ferramentas que } \\
\text { potencializam o trabalho interprofissional e a integralidade do cuidado em saúde, em se tratando de atenção } \\
\text { terciária, em um hospital-escola. }\end{array}$ \\
\hline Brito JSS, 2017 & $\begin{array}{l}\text { Realizar uma análise da RMS enquanto uma estratégia de } \\
\text { educação interprofissional em Saúde. }\end{array}$ & $\begin{array}{l}\text { A RMS apresenta potencial pedagógico para a EIP e para a Prática Interprofissional Colaborativa, mas diversos } \\
\text { fatores, tanto macro quanto micropolíticos, podem representar impedimentos ao desenvolvimento destas } \\
\text { possibilidades. }\end{array}$ \\
\hline Silva AS, 2017 & $\begin{array}{l}\text { Compreender o grau de satisfação acerca do programa RMS com } \\
\text { ênfase em onco-hematologia na visão de residentes e preceptores } \\
\text { sobre o ensino interprofissional em saúde. }\end{array}$ & $\begin{array}{l}\text { Os residentes mostraram-se satisfeitos em fazer parte do programa em andamento. Por outro lado, percebem a } \\
\text { necessidade de um melhor aperfeiçoamento do "ser preceptor" e sugeriram melhorias para qualificar o programa, } \\
\text { que contempla condições reais de aprendizagem. Através de ações de promoção da saúde e atuação em equipes } \\
\text { interprofissionais de diferentes áreas, proporciona novas possibilidades de incorporação às políticas públicas de } \\
\text { saúde como modelo de parceria universidade/serviço. }\end{array}$ \\
\hline
\end{tabular}


Research, Society and Development, v. 11, n. 2, e15711225510, 2022

(CC BY 4.0) | ISSN 2525-3409 | DOI: http://dx.doi.org/10.33448/rsd-v11i2.25510

\begin{tabular}{|c|c|c|}
\hline $\begin{array}{r}\text { Arruda GMM } \\
2018\end{array}$ & $\begin{array}{l}\text { nalisar a colaboração interprofissional em um programa de } \\
\text { sidência multiprofissional em Saúde da Família por meio da } \\
\text { oologia de D’Amour e colaboradores. }\end{array}$ & $\begin{array}{l}\text { Observou-se o fortalecimento de todos os indicadores da colaboração interprofissional (governança, visão e } \\
\text { objetivos compartilhados, formalização e internalização), tanto pela condução político-pedagógica do programa } \\
\text { quanto pelo processo de trabalho na Estratégia Saúde da Família. }\end{array}$ \\
\hline Aguiar RBP & $\begin{array}{l}\text { Analisar a percepção dos preceptores acerca do processo de } \\
\text { interdisciplinaridade na residência multiprofissional de neurologia } \\
\text { e neurocirurgia do HGF no Ceará. }\end{array}$ & $\begin{array}{l}\text { Dentre as três dimensões da Escala de Medida da Disponibilidade para Aprendizagem Interprofissional os } \\
\text { entrevistados concordaram totalmente com o que é preconizado na dimensão "Trabalho em equipe e colaboração e } \\
\text { atenção centrada no paciente", porém o fator "Identidade profissional", obteve uma maior concentração nas opções } \\
\text { discordo totalmente e discordo, e encontra-se em zona de alerta. O papel do preceptor no processo ensino- } \\
\text { aprendizagem, sua interação com as diversas áreas na construção da prática profissional e a necessidade de } \\
\text { construção da identidade da residência surgem como situações vivenciadas pelos preceptores. }\end{array}$ \\
\hline $\begin{array}{r}\text { Casanova } \\
201\end{array}$ & $\begin{array}{l}\text { Analisar os princípios, concepções e práticas da EIP, de acordo } \\
\text { com a perspectiva dos residentes, e no projeto pedagógico (PP) de } \\
\text { IES do Estado de São Paulo. }\end{array}$ & $\begin{array}{l}\text { Os resultados do instrumento Likert evidenciam satisfação dos residentes com a formação para prática colaborativa. } \\
\text { Os PPP analisados evidenciam potencialidades que explicitam ações de trabalho que conduzem à responsabilização } \\
\text { das equipes no que tange ao cuidado e à capacidade de resolver os problemas da saúde. A percepção dos residentes } \\
\text { sobre o desenvolvimento de competências para a prática colaborativa evidenciou a sua satisfação. Entre os desafios } \\
\text { encontrados estão a condição de trabalho pela expressiva demanda e a visão especializada que dificulta o } \\
\text { atendimento na perspectiva da integralidade do cuidado. }\end{array}$ \\
\hline $\begin{array}{r}\text { Albuquerqu } \\
\text { al., } 2\end{array}$ & $\begin{array}{l}\text { Avaliar a percepção sobre a formação interprofissional e o } \\
\text { desenvolvimento de competências para práticas colaborativas de } \\
\text { nutricionistas residentes inseridos no contexto das Residências } \\
\text { Multiprofissionais em Saúde do Nordeste brasileiro. }\end{array}$ & $\begin{array}{l}\text { Os nutricionistas residentes apresentam a mesma compreensão que os demais residentes das outras categorias } \\
\text { profissionais sobre o desenvolvimento das práticas colaborativas nas RMS. Observou-se que mesmo diante dos } \\
\text { desafios postos pelos programas de residências, os residentes consideram que a modalidade possibilita o } \\
\text { desenvolvimento de competências para a prática colaborativa. }\end{array}$ \\
\hline $\begin{array}{l}\text { Arnemann CT et al., } \\
\qquad 2018\end{array}$ & ã̃o. & $\begin{array}{l}\text { As melhores práticas identificadas são: a consulta multiprofissional, o acolhimento dos residentes e as ações } \\
\text { integradas entre as diferentes ênfases da residência. }\end{array}$ \\
\hline $\begin{array}{c}\text { Camargo FC } \\
2018\end{array}$ & dência & ada governabilidade para apoiar a reestruturação do processo de trabalho dessas \\
\hline $\begin{array}{r}\text { Evangelista } \\
\text { al., } 201\end{array}$ & $\begin{array}{l}\text { Compreender o contexto histórico e político-pedagógico da } \\
\text { implementação da RMS e a percepção dos atores sociais } \\
\text { envolvidos na implementação desta sobre os seus reflexos na } \\
\text { organização da atenção psicossocial. }\end{array}$ & $\begin{array}{l}\text { A RMS disparou avanços na organização na atenção psicossocial nos } \\
\text { Rede de Atenção Psicossocial, através da atuação interprofissional, foss }\end{array}$ \\
\hline Costa BF, & $\begin{array}{l}\text { Discutir as potências e limitações da realidade de trabalho da } \\
\text { Estratégia Saúde da Família enquanto espaço de implementação } \\
\text { da Educação Interprofissional a partir das percepções dos } \\
\text { Residentes da Residência Multiprofissional em Atenção Básica e } \\
\text { Residência de Medicina da Família e Comunidade. }\end{array}$ & $\begin{array}{l}\text { A partir da realização de uma oficina, da implementação de práticas interprofissionais na realidade da produção dos } \\
\text { serviços de saúde da atenção básica e grupos focais foram construídas as categorias: Aprendizado Mútuo, } \\
\text { Aprendizagem Compartilhada, Comunicação Interprofissional, Eficácia na Resolutividade do Problema, Atenção } \\
\text { Integral em Saúde, Valorização da Participação do Usuário, Troca de Habilidades Entre os Profissionais, } \\
\text { Conhecimento de Outras Profissões, Melhoria de Habilidade, Respeito Mútuo, Cuidado Integral ao Usuário. }\end{array}$ \\
\hline Lago LPM et al & $\begin{array}{l}\text { Refletir sobre possibilidades, limites e desafios do uso da análise } \\
\text { institucional de práticas profissionais (AIPP) como dispositivo } \\
\text { para a formação interprofissional em um programa de residência }\end{array}$ & $\begin{array}{l}\text { O dispositivo de AIPP possibilitou um movimento de autoanálise da formação. Seu uso evidenciou atravessamentos } \\
\text { na formação em serviço que impedem as práticas de caráter colaborativo: a exigência da produção em massa, } \\
\text { principalmente por atendimento individual especializado; a centralidade no profissional médico; o pouco tempo }\end{array}$ \\
\hline
\end{tabular}


Research, Society and Development, v. 11, n. 2, e15711225510, 2022

(CC BY 4.0) | ISSN 2525-3409 | DOI: http://dx.doi.org/10.33448/rsd-v11i2.25510

\begin{tabular}{|c|c|c|}
\hline & multiprofissional em saúde. & para reflexão nos espaços de atuação; e o não encontro entre diferentes profissionais nos serviços. \\
\hline Leitão BFB, 2018 & $\begin{array}{l}\text { Compreender, sob a perspectiva dos residentes egressos, como a } \\
\text { integralidade do cuidado se expressa no processo formativo da } \\
\text { Residência Integrada em Saúde com ênfase em Cancerologia. }\end{array}$ & $\begin{array}{l}\text { As análises revelaram que os principais sentidos da integralidade reconhecidos pelos residentes aparecem } \\
\text { associados à dimensão da interprofissionalidade e à perspectiva da atenção em rede, embora estes se encontrem } \\
\text { atravessados por vários obstáculos e desafios próprios do cenário hospitalar. }\end{array}$ \\
\hline $\begin{array}{l}\text { Medeiros MSMF, } \\
\quad 2018\end{array}$ & $\begin{array}{l}\text { Compreender a percepção dos alunos das Residências Médica e } \\
\text { Multiprofissional sobre o trabalho interprofissional desenvolvido } \\
\text { entre eles em uma maternidade escola. }\end{array}$ & $\begin{array}{l}\text { Os resultados sugerem a existência de algumas iniciativas de EIP promovidas entre as residências, porém as } \\
\text { experiências interprofissionais entre residentes médicos e multiprofissionais ocorrem apenas em alguns campos de } \\
\text { prática. Em outros cenários da instituição, as experiências não se desenvolvem ou acontecem de forma não } \\
\text { legitimada. }\end{array}$ \\
\hline Wetzel C et a & $\begin{array}{l}\text { Analisar a formação interprofissional em serviço a partir da } \\
\text { perspectiva de trabalhadores de um Centro de Atenção } \\
\text { Psicossocial. }\end{array}$ & $\begin{array}{l}\text { A RMS constitui-se como espaços de trocas, crescimento, aprendizado, de educação permanente e de formação para } \\
\text { a Saúde Mental na perspectiva da Reforma Psiquiátrica. Mesmo havendo o distanciamento dos residentes do } \\
\text { serviço, a relação estabelecida no encontro trabalhadores-residentes estimulou processos de mudança em relação a } \\
\text { formas já instituídas de pensar o processo de trabalho. }\end{array}$ \\
\hline Lago LPM, 2019 & $\begin{array}{l}\text { Analisar as práticas profissionais de residentes multiprofissionais } \\
\text { em saúde que favorecem ou não a colaboração interprofissional e } \\
\text { a integralidade do cuidado na atenção básica. }\end{array}$ & $\begin{array}{l}\text { Observou-se tensões entre a reprodução da especialidade e formação uniprofissional, e a criação de espaços para a } \\
\text { prática colaborativa interprofissional. O modelo de gestão universitária centralizada e produtivista fragilizam os } \\
\text { processos pedagógicos colaborativos e criam limites ao cuidado integral. Os residentes puderam repensar a } \\
\text { dinâmica institucional na formação comum, no processo de trabalho-aprendizagem e questionar a reprodução do } \\
\text { instituído de formação uniprofissional e cuidado centrado no profissional médico. }\end{array}$ \\
\hline Alves & $\begin{array}{l}\text { Relatar a colaboração interprofissional vivenciada por uma } \\
\text { enfermeira de um programa de residência multiprofissional em } \\
\text { saúde. }\end{array}$ & $\begin{array}{l}\text { A RMS proporciona o conhecimento e os espaços para a colaboração interprofissional, porém não está totalmente } \\
\text { implementada na rotina do programa, sendo necessário estudar melhores meios para aprimorar a metodologia. }\end{array}$ \\
\hline $\begin{array}{l}\text { Henrique RS et al., } \\
\qquad 2019\end{array}$ & $\begin{array}{l}\text { Relatar experiências vividas consideradas potentes para a } \\
\text { construção de um processo de trabalho integrado, qualificado e } \\
\text { crítico. }\end{array}$ & $\begin{array}{l}\text { Foi observada a incompatibilidade entre os processos formativos propostos pela RMS e aqueles vividos pelas } \\
\text { diferentes graduações, produzindo uma atuação segmentada e centrada no profissional médico. Todas as atividades } \\
\text { teóricas e teórico-práticas no decorrer da residência são coletivas e multiprofissionais utilizando ferramentas para o } \\
\text { trabalho interprofissional como: matriciamento, reuniões de equipe, atividades de educação permanente, } \\
\text { interconsultas e grupos. }\end{array}$ \\
\hline $\begin{array}{l}\text { Lewgoy AMB et al., } \\
\qquad 2019\end{array}$ & $\begin{array}{l}\text { Descrever a experiência em educação Interprofissional de um dos } \\
\text { programas da Residência Integrada Multiprofissional em Saúde } \\
\text { Hospitalar na perspectiva da tutoria em um hospital-escola do sul } \\
\text { do Brasil. }\end{array}$ & $\begin{array}{l}\text { A tutoria de campo possibilitou o trabalho interprofissional colaborativo, ao privilegiar: a) nas supervisões } \\
\text { acadêmicas assistenciais, o aprendizado entre os residentes, através do compartilhamento e do reconhecimento das } \\
\text { potencialidades individuais e coletivas de cada profissão; b) nas oficinas de orientação junto aos familiares e } \\
\text { acompanhantes, permitindo que as residentes se reconhecessem em suas profissões e aprendessem sobre as outras; } \\
\text { c) no Programa de Controle de Infecção, pela inclusão do módulo teórico da ênfase em EIP com supervisão de uma } \\
\text { tutoria com experiência em atividades de ensino e extensão envolvendo diferentes profissões da saúde, que } \\
\text { estimulou a interação da equipe a dar continuidade a verificar sistematicamente os indicadores. }\end{array}$ \\
\hline $\begin{array}{l}\text { Lima ICBF, Passos } \\
\quad \text { ICF, } 2019\end{array}$ & $\begin{array}{l}\text { Analisar, à luz das discussões sobre educação interprofissional e } \\
\text { práticas colaborativas no contexto da reforma psiquiátrica, o PPP } \\
\text { de um programa de residências integradas em saúde mental. }\end{array}$ & $\begin{array}{l}\text { Entre os achados, destaca-se a potencialidade do programa para o fortalecimento do processo de } \\
\text { desinstitucionalização e de qualificação da política pública de saúde mental. Por meio do desenvolvimento de } \\
\text { competências necessárias para a realização de um trabalho coletivo e comprometido com a integralidade da } \\
\text { assistência em saúde, o programa reforça a necessidade da interprofissionalidade e das práticas colaborativas, indo }\end{array}$ \\
\hline
\end{tabular}


Research, Society and Development, v. 11, n. 2, e15711225510, 2022

(CC BY 4.0) | ISSN 2525-3409 | DOI: http://dx.doi.org/10.33448/rsd-v11i2.25510

\begin{tabular}{|c|c|c|}
\hline & & além do tecnicismo. \\
\hline $\begin{array}{c}\text { Rebouças RRM et al., } \\
2019\end{array}$ & $\begin{array}{l}\text { Compreender os limites e possibilidades de atuação } \\
\text { interprofissional da equipe de residentes multiprofissionais da } \\
\text { Residência Integrada em Saúde no contexto hospitalar. }\end{array}$ & $\begin{array}{l}\text { Os participantes da pesquisa relacionaram o conceito dos termos multiprofissionalidade e interprofissionalidade à } \\
\text { importância da comunicação e troca de conhecimento entre os profissionais, consideraram que a divisão de trabalho } \\
\text { no hospital interfere na atuação interprofissional e apontaram o trabalho conjunto, visão ampliada e embasamento } \\
\text { científico como estratégias para um cuidado integral. }\end{array}$ \\
\hline Sanches MV, 2019 & $\begin{array}{l}\text { Compreender como se deu o processo de implantação e } \\
\text { desenvolvimento do programa de RMS em Saúde Mental com } \\
\text { ênfase em dependência química, considerando o enfoque nos } \\
\text { processos de aprendizagem pautados pela educação } \\
\text { interprofissional colaborativa. }\end{array}$ & $\begin{array}{l}\text { Constatou-se que a inserção dos residentes qualifica os serviços e as equipes de saúde. Os obstáculos identificados } \\
\text { estão relacionados às políticas públicas, ao pouco reconhecimento dos serviços quanto a atividades dos profissionais } \\
\text { e residentes, falta de repasse financeiro para preceptores, docentes e demais colaboradores do programa, ausência de } \\
\text { reposição de profissionais desligados dos serviços. }\end{array}$ \\
\hline Dantas BT, 2020 & $\begin{array}{l}\text { Implantar estratégias de ensino aprendizagem para a prática de } \\
\text { competências do trabalho em equipe entre alunos de uma } \\
\text { Residência Integrada Multiprofissional em Saúde. }\end{array}$ & $\begin{array}{l}\text { O estudo mostra a importância de práticas das equipes multiprofissionais com desenvolvimento de competências } \\
\text { quando } 89,8 \% \text { concordam que aprender com outros profissionais de saúde é vantagem para desenvolvimento de } \\
\text { habilidades do trabalho em equipe. O uso de metodologias ativas e avaliação formativa resultam em melhoria das } \\
\text { competências, comprovada na análise das avaliações entre as atividades de práticas de simulação realística. }\end{array}$ \\
\hline $\begin{array}{l}\text { Querido DL et al., } \\
2020\end{array}$ & $\begin{array}{l}\text { Conhecer as percepções dos atores envolvidos em um programa } \\
\text { de Residência Multiprofissional sobre os fatores que influenciam a } \\
\text { educação interprofissional. }\end{array}$ & $\begin{array}{l}\text { Apesar da EIP não ser estimulada na graduação de metade dos participantes, a maioria dos preceptores consegue } \\
\text { desenvolver suas atividades junto aos residentes nessa perspectiva e isso é percebido também pelos egressos. Dentre } \\
\text { os desafios encontrados, destaca-se o processo de trabalho, o processo de formação dos preceptores, a comunicação } \\
\text { interprofissional e a organização do serviço de saúde. }\end{array}$ \\
\hline
\end{tabular}

Fonte: Dados da pesquisa. 


\section{RMS como cenários para a promoção da EIP e das práticas colaborativas}

Esta dimensão analítica pôde ser percebida nos estudos que buscaram introduzir atividades de promoção da EIP dentro dos programas de RMS (Câmara, 2014; Motta \& Pacheco, 2014; Soares, 2015; Santos et al., 2016; Frossard \& Silva, 2016; Arnemann et al., 2018; Camargo et al., 2018; Costa, 2018; Lago et al., 2018; Henrique et al., 2019; Lewgoy et al.,2019; Dantas, 2020); naqueles que identificaram cenários favoráveis através de dispositivos institucionais, como os PPP (Miranda Neto et al., 2015; Arruda et al., 2016; Casanova et al., 2018; Evangelista et al., 2018; Lima \& Passos, 2019); e nos que analisaram a percepção e a disponibilidade dos atores para a aprendizagem interprofissional compartilhada (Perego \& Batista, 2016; Aguiar, 2018; Leitão, 2018; Dantas, 2020).

Os principais elementos encontrados nesta categoria foram: a presença de currículo baseado em competências, a educação pelo trabalho, a inserção dos residentes em equipes multiprofissionais, educação permanente como princípio pedagógico, presença de metodologias ativas, foco na integralidade e avaliações formativas. Um artigo incluído nesta revisão identificou a adoção especificamente da EIP como referencial teórico de um dos programas de RMS analisados (Miranda Neto et al., 2015).

Em relação às metodologias e processos avaliativos utilizados, um estudo demonstrou que o uso de avaliação formativa, juntamente com as metodologias ativas, resulta em melhoria das competências para o trabalho em equipe (Dantas, 2020). Cabe destacar que a essência formativa, diferente da avaliação somativa que considera apenas o resultado do fim do processo, leva em consideração toda a trajetória de ensino-aprendizagem. Através de avaliações contínuas, oportuniza-se aos estudantes reflexões e ajustes de condutas ao longo do processo, e proporciona-se a autoavaliação e a autorregulação entre seu nível de aprendizado e nível de capacitação a ser alcançado (Fernandes, 2006).

Dentre as práticas presentes nas RMS que promovem a EIP foram identificadas: a construção de projeto terapêutico singular, ações integradas entre as diferentes áreas da residência, matriciamento, reuniões de equipe, atividades de educação permanente e interconsultas. Estes achados convergem para a conclusão de que a residência possui potencial pedagógico para o desenvolvimento da EIP, proporciona espaços para a prática da colaboração interprofissional, e se configura como modalidade educacional propícia para o treinamento interprofissional.

Corroborando com estes resultados, Vasconcelos et al. (2016a), ao analisar a percepção de profissionais da Atenção Básica sobre as RMS, identificaram que a residência trouxe a ampliação da visão sobre o trabalho interprofissional na prática, além do conhecimento sobre áreas profissionais antes não conhecidas, e que esta é vista como uma estratégia de educação permanente promovendo momentos de troca de saberes e potencializando a escuta e o diálogo entre equipes. Os diversos cenários de prática nos quais os residentes são inseridos viabilizam o contato com diferentes profissionais e oferecem possibilidades de encontros e interações que ampliam o leque de reflexões para lidar com as complexidades das necessidades em saúde (Rodrigues, 2016).

Rodrigues (2016) argumenta que o trabalho em equipe proporcionado pelas RMS traz em si a lógica das trocas, conversas, reuniões e articulações das ações, devendo ser uma diretriz presente no trabalho de todos os profissionais. Segundo Bones et al. (2015), a proposta da residência multiprofissional permite atuar conscientemente de modo interdisciplinar, no qual a escolha da organização do processo de trabalho contribua para auxiliar na definição dos papeis profissionais, dos seus objetivos e relações conforme o escopo das práticas colaborativas em projetos de EIP com vistas à excelência assistencial dos serviços de saúde.

\section{RMS e o desenvolvimento de competências para o trabalho interprofissional e transformação das práticas}

Os achados referentes à esta categoria dizem respeito às dinâmicas proporcionadas pelas RMS para a aquisição de competências relacionadas à EIP e ao potencial destas em promover mudanças nos ambientes e processos de trabalho dos 
serviços. Foram relatadas experiências que privilegiam o compartilhamento e reconhecimento das potencialidades individuais e coletivas de cada profissão, além do aprendizado sobre estas, focando na integralidade do cuidado e nas necessidades dos usuários (Câmara, 2014; Motta \& Pacheco, 2014; Santos et al., 2016; Araújo et al., 2017; Brito, 2017; Arruda et al.,2018; Camargo, 2018; Evangelista et al., 2018; Wetzel et al.,2018; Alves, 2019; Henrique et al., 2019; Sanches, 2019; Querido et al., 2020).

O aprendizado sobre competências comuns e colaborativas foi identificado pelos residentes participantes dos estudos, ao mesmo tempo em que se reconheceu a importância de fortalecer as identidades profissionais. Assim, os residentes consideram que as RMS possibilitam o desenvolvimento de competências para uma prática colaborativa em saúde no contexto do SUS (Casanova et al., 2015; Miranda Neto, 2015; Albuquerque et al., 2018; Casanova et al., 2018).

Aguilar-da-Silva et al. (2011) apontaram em seu estudo sobre percepções de estudantes de diferentes cursos da saúde em relação ao trabalho em equipe e a colaboração que, para estes, parece não existir clareza de quais são as atribuições específicas de cada profissional para o estabelecimento das competências profissionais. Porém, a maioria dos estudantes concordou que a aprendizagem compartilhada os ajuda a compreender as próprias limitações e que o trabalho em equipe proporciona de fato um aprendizado efetivo. Para Barr (1998), a EIP sempre deverá ser incluída na formação em saúde em razão da sua relevância para o desenvolvimento de competências para a educação e o trabalho interprofissional: competências específicas de cada profissão, competências comuns a todas as profissões e competências colaborativas, necessárias para a reconfiguração das relações profissionais em prol da qualidade da atenção à saúde.

Os estudos que avaliaram a percepção dos residentes e preceptores sobre o desenvolvimento de competências para a prática colaborativa identificaram satisfação em relação à formação ofertada pelas RMS. $\mathrm{O}$ trabalho em equipe, o respeito mútuo, o reconhecimento do próprio papel e do outro profissional, a troca de experiências, de saberes e de corresponsabilidade na rotina de trabalho da equipe foram elementos identificados condizentes com a EIP (Silva, 2017; Casanova et al., 2018).

O potencial de mudanças dos programas está diretamente relacionado com as estratégias pedagógicas desenvolvidas nos cenários educativos. Demonstrou-se que a presença dos programas de RMS tem o potencial de qualificar os trabalhadores dos serviços envolvidos através da relação destes com os residentes. A aprendizagem conjunta e a troca de informações proporcionada pelos programas estimula processos de mudança em relação aos modelos de trabalho já estabelecidos. Autores argumentam que a relação estabelecida no encontro entre trabalhadores e residentes estimula processos de mudança em relação a formas já instituídas de pensar o processo de trabalho (Wetzel et al., 2018).

Nesta direção, outros estudiosos afirmam que as residências promovem a formação tanto para os residentes quanto para os profissionais de saúde, pois levam os envolvidos à reflexão e à consequente transformação dos modelos e modos de operar em saúde (Uchôa-Figueiredo et al., 2016). Vasconcelos et al. (2016a; 2016b) encontraram que a inserção dos residentes diminuiu o tempo necessário para visitas domiciliares de agentes comunitários de saúde na atenção básica devido às orientações e informações trazidas pelas trocas com os grupos de residentes. Observam ainda que, mesmo sem o reconhecimento dos profissionais dos serviços quanto à importância da integração ensino-serviço-comunidade, as ações e discussões compartilhadas disparam reflexões sobre o cotidiano do trabalho gerando mudanças nas práticas profissionais.

As RMS, ao proporcionar saídas das unidades de saúde, o conhecimento do território e a articulação com as atividades na universidade, possibilitam a realização de um trabalho integrado. Este arranjo, ligado à estruturação das residências, traz novas possibilidades e estratégias de educação permanente que reverberam na transformação de modelos e processos de trabalho em saúde (Rodrigues, 2016). 


\section{Limites e desafios à EIP nas RMS}

Esta categoria apresenta os principais limites e desafios para a implantação da EIP nas RMS encontrados nos estudos analisados e se concentraram nos seguintes elementos: fundamentação e compreensão teórica sobre a EIP; pouca compreensão sobre os papeis dos residentes, preceptores e profissionais de diferentes áreas; estruturação dos cenários de prática e organização dos serviços; rigidez curricular; cargas de trabalho e horária excessivas; formação uniprofissional; comunicação e trocas entres profissionais; incentivo político e financeiro (Miranda Neto, 2015; Frossard \& Silva, 2016; Arruda et al, 2016; Medina, 2016; Casanova et al., 2018; Costa, 2018; Lago et al., 2018; Leitão, 2018; Medeiros, 2018; Lago, 2019; Rebouças et al., 2019; Sanches, 2019; Querido et al, 2020).

Os estudos mostraram que ainda há confusão sobre os conceitos de multiprofissionalidade e interprofissionalidade (Dias et al., 2016; Araújo et al., 2017), e sobre as funções e responsabilidades dos residentes e outros profissionais (Medina, 2016; Aguiar, 2018; Sanches, 2019). Estes aspectos levam à fragmentação das ações, dificultando a integralidade do cuidado preconizada pelos programas e pelo SUS.

Desta forma, a fundamentação e compreensão teórica sobre a EIP é imprescindível para a mudança da mentalidade e superação da fragmentação das ações em saúde. A delimitação dos limites conceituais da EIP é importante para alinhar a produção teórico-conceitual em torno da construção e consolidação do SUS com os pressupostos da educação e do trabalho interprofissional. Além do entendimento sobre a prática da EIP, a real integração entre as IES, o serviço, a comunidade e a gestão se faz necessária para colocar a teoria em prática, sobrepujando a lógica do mercado, a disputa entre categorias profissionais e o corporativismo (Brasil, 2017).

Para Rodrigues (2016), o residente não deve ser visto como mais um membro da equipe que responde individualmente às demandas ou supre a necessidade imediata de recursos humanos. Apesar de apresentar autonomia como profissional para exercer suas atribuições específicas, a articulação com a formação torna diferenciada a sua inserção nos serviços. Estudo realizado por Vasconcelos et al. (2016a) demonstrou que trabalhadores dos serviços reconhecem os residentes como profissionais com autonomia para realizar condutas sem limitações ou necessidade de supervisão constante. A dualidade existente quanto ao papel dos residentes (aluno versus profissional) poderia ser mais bem compreendida com a construção de uma identidade da residência dentro dos serviços para todos os trabalhadores envolvidos, sendo essa uma necessidade reconhecida pelo estudo de Aguiar (2018).

Em relação aos serviços, foram mencionados como desafios a contratação e reposição insuficientes de profissionais, ocasionando altas demandas e exigências de produção em massa. Além disso, o número insuficiente de profissionais para acompanhar o andamento das atividades dos residentes no cotidiano e a necessidade de qualificação e aperfeiçoamento dos preceptores também foram mencionados nos estudos incluídos (Frossard \& Silva, 2016; Medina, 2016; Silva, 2017; Sanches, 2019).

Cabe mencionar o papel dos preceptores como "orientadores de aprendizagem", os quais possuem o propósito de promover o autodescobrimento, gerando reflexões, críticas e formulação de perguntas através das metodologias ativas. Desta forma, estes profissionais atuariam na instrumentalização dos residentes para interatuar de forma adequada na resolução de problemas e realizar as transformações necessárias (Ferreira, 2009). Nesse sentido, autores advogam que a preceptoria deve estar incluída nas políticas de qualificação e valorização dos profissionais de saúde, competindo à gestão nos âmbitos estadual e municipal o estímulo através de incentivos à qualificação profissional, progressão funcional ou na carreira, de gestão de carga horária, dentre outros, considerando indissociável a relação entre ensino e serviço (Araújo et al., 2017).

A carga horária excessiva dos residentes, que limita o tempo para reflexão nos espaços de atuação, foi apontada como um desafio por alguns estudos (Frossard \& Silva, 2016; Lago et al., 2018) e corroborada por Rodrigues (2016) que considera necessária a discussão de revisão desta carga horária nos espaços organizativos e instâncias legais dos programas de RMS. Por 
outro lado, Vasconcelos et al. (2016a) consideram que a extensa carga horária em atividades práticas propicia um maior contato dos residentes com o planejamento e execução das tarefas, ampliando sua participação e incorporação às equipes.

Outro aspecto referido foi a existência de tensões entre a reprodução da formação especializada uniprofissional e a criação de espaços para a prática colaborativa interprofissional (Lago et al., 2018; Henrique et al., 2019; Lago, 2019; Querido et al., 2020). Foi citado o esforço necessário para a construção de uma plataforma de atuação única e manutenção do vínculo existente entre os membros da equipe, visto que os olhares sobre a mesma realidade nem sempre eram concordantes (Lago, 2019). Em estudo de Câmara (2014), a experiência de uma oficina de EIP para residentes de $1^{\circ}$ e $2^{\circ}$ ano facilitou a comunicação entre os participantes, e ampliou e aproximou os olhares dos diferentes profissionais.

Neste sentido, a comunicação interprofissional foi considerada como um desafio, reafirmado pelas dificuldades de encontro entre diferentes profissionais nos serviços, pelo isolamento dos residentes no segundo ano de residência, e pela centralidade na figura do profissional médico e pouca interação com residentes médicos (Soares, 2015; Lago et al., 2018; Medeiros, 2018 Henrique et al, 2019; Lago, 2019). A ausência de um espaço democrático consolidado de discussão entre os residentes, coordenadores e gestores dos programas foi citada, assim como no estudo de Vasconcelos et al. (2016a), no qual a desarticulação de comunicação entre as diferentes frentes de inserção da residência foi mencionada como um desafio operacional e pedagógico para as equipes.

A reflexão de elementos mais macrossociológicos deve acompanhar o debate sobre a interprofissionalidade, considerada uma questão estruturante para o SUS. Algumas resistências fazem parte da própria arquitetura universitária, como o perfil de gestão (Brasil, 2017). Obstáculos quanto às políticas públicas e atual contexto político das residências multiprofissionais, sustentabilidade financeira dos programas e repasses financeiros à preceptores, docentes e demais colaboradores também foram apontados como limites ao exercício da EIP nas RMS (Arruda et al, 2016; Frossard \& Silva, 2016; Sanches, 2019).

\section{Considerações Finais}

Diferentes visões sobre o trabalho em equipe interprofissional e concepções sobre o trabalho em saúde dificultam o processo de ensino-aprendizagem compartilhado, proveniente, muitas vezes, da própria formação dos sujeitos em graduações e modelos de formação uniprofissionais. Os currículos organizados de maneira uniprofissional, presentes em grande parte das graduações, é um fator limitante aos pressupostos da EIP.

As residências multiprofissionais, ao colocar diversos profissionais de saúde com formações distintas para atuarem juntos, favorecem o compartilhamento de práticas e procedimentos, a identificação das necessidades de saúde e a atuação centrada no paciente. Os estudos encontrados nesta pesquisa mostraram que os programas de RMS contribuem para o reconhecimento de competências comuns sem trazer prejuízos à identidade profissional.

A maioria dos estudos identificou a colaboração profissional como estratégia de melhoria da qualidade da atenção, e dispositivos utilizados nos programas como currículo baseado em competências, avaliação formativa e metodologias ativas foram identificados, estando de acordo com o preconizado pela perspectiva da EIP. Além disso, os estudos revelaram aspectos presentes no contexto das residências multiprofissionais como comunicação, compartilhamento e reconhecimento das potencialidades individuais e coletivas de cada profissão, e trocas com profissionais dos serviços, que facilitam a abordagem da educação interprofissional e da prática colaborativa.

Foram identificadas fragilidades na compreensão dos conceitos 'multiprofissional' e 'interprofissional', nas experiências entre residentes médicos e multiprofissionais e no esclarecimento do papel dos residentes nas equipes. Limitações quanto à estruturação dos cenários de prática e organização dos serviços, ao isolamento dos residentes no segundo ano, a cargas de trabalho e horária excessivas e à reprodução do modelo biomédico também foram observadas. 
O envolvimento da gestão também se mostrou fundamental para o fortalecimento das residências como dispositivos de educação permanente, e possivelmente de educação e trabalho interprofissionais. Porém, o baixo incentivo político e financeiro, e a gestão universitária centralizada e produtivista foram apresentados como barreiras à inserção da EIP nas RMS.

\section{Referências}

Aguiar, R. B. P. L. (2018). Interdisciplinaridade e prática colaborativa na percepção dos preceptores de um programa de residência multiprofissional em neurologia e neurocirurgia (Dissertação de mestrado). Centro Universitário Christus, Fortaleza, CE.

Aguilar-da-Silva, R. H., Scapin, L. T., \& Batista, N.A. (2011). Avaliação da formação interprofissional no ensino superior em saúde: aspectos da colaboração e do trabalho em equipe. Avaliação, 16(1), 167-184.

Albuquerque, E. R. N., Santana, M. C. C. P., \& Rossit, R. A. S. (2018). Residências multiprofissionais em saúde como fomentadoras da formação interprofissional: percepção de nutricionistas sobre as práticas colaborativas. Demetra, 13(3), 605-619.

Alves, I. M. F. (2019). A colaboração interprofissional em um programa de residência multiprofissional em saúde: um relato de experiência (Trabalho de conclusão de curso). Universidade Federal do Rio Grande do Norte, Caicó, RN.

Araújo, T. A. M., Vasconcelos, A. C. C. P., Pessoa, T. R. R. F., \& Forte, F. D. S. (2017). Multiprofissionalidade e interprofissionalidade em uma residência hospitalar: o olhar de residentes e preceptores. Interface (Botucatu), 21(62), 601- 613.

Arnemann, C. T., Kruse, M. H. L., Gastaldo, D., Jorge, A. C. R., Silva, A. L., \& Margarites, A. G. F. (2018). Práticas exitosas dos preceptores de uma residência multiprofissional: interface com a interprofissionalidade. Interface (Botucatu), 22(2), 1635-1646.

Arruda, G. M. M. S., Barreto, I. C. H. C., Pontes, R. J., \& Loiola, F. A. (2016). Educação interprofissional na pós-graduação em saúde: dimensões pedagógicas interprofissionais em uma Residência Multiprofissional em Saúde da Família. Tempus, actas de saúde colet, 10(4), $187-214$.

Arruda, G. M. M. S., Barreto, I. C. H. C., Ribeiro, K. G., \& Frota, A. C. (2018). The development of interprofessional collaboration in different contexts of multidisciplinary residency in Family Health. Interface (Botucatu), 22(1), 1309-1323.

Barr, H. (1998). Competent to collaborate: Towards a competency-based model for interprofessional education. Journal of Interprofessional Care, 12, 181187.

Barr, H., \& Low, H. (2013). Introdução à Educação Interprofissional. Centro para o Avanço da Educação Interprofissional (CAIPE).

Barr, H. (2015). Interprofessional Education: the genesis of a global movement. Center for the Advancement of Inteprofessional Care. London: Centre for Advancement of Interprofessional Education.

Bezerra, R. K. C., Oliveira, A. M. A., Silva, E. S., Lopes, L. H. B., Fernandes, C. C., Fernandes, T. A. A. de M., \& Nascimento, E. G. C. do. (2020). Impact of interprofessional education on graduate graduation: an integrative review. Research, Society and Development, 9(11).

Bones, A. A. N. S., Cazella, S. C., Weber, L. S., Costa, M. R. R., Saraiva, M. P., \& Bopsin, M. R. (2015). Residência multiprofissional tecendo práticas interdisciplinares na prevenção da violência. ABCS Health Sci., 40(3), 343-347.

Brasil. Ministério da Saúde. Secretaria de Gestão do Trabalho e da Educação na Saúde. Departamento de Gestão da Educação na Saúde. (2017). Relatório final da oficina de alinhamento conceitual sobre educação e trabalho interprofissional em saúde (1. ed.). Brasília, DF: Ministério da Saúde.

Brasil. Ministério da Saúde. Secretaria de Gestão do Trabalho e da Educação na Saúde. Departamento de Gestão da Educação na Saúde. (2018a). Construindo caminhos possíveis para a Educação Interprofissional em Saúde nas Instituições de Ensino Superior do Brasil. Brasília, DF: Ministério da Saúde, Secretaria de Gestão do Trabalho e da Educação na Saúde, Departamento de Gestão da Educação na Saúde.

Brasil. Ministério da Saúde, Secretaria de Gestão do Trabalho e da Educação na Saúde. (2018b). Política Nacional de Educação Permanente em Saúde: o que se tem produzido para o seu fortalecimento? Brasília: Departamento de Gestão da Educação na Saúde.

Brito, J. S. S. (2017). Análise da educação interprofissional em saúde através da experiência da residência multiprofissional em saúde da família (Dissertação de mestrado). Instituto Aggeu Magalhães, Fundação Oswaldo Cruz, Recife, PE.

Câmara, A. M. C. S. (2014). Oficina de educação interprofissional para a residência multiprofissional. Cad edu saude e fis., 1(1), 27-34.

Camargo, F. C., Garcia, L. A. A., Walsh, I. A. P., Emílio, M. M., Coelho, V. H. M., \& Pereira, G. A. (2018). Formação para o trabalho na estratégia saúde da família: experiência da residência multiprofissional em saúde. Rev Enferm Atenção Saúde, 7(1), 190-199.

Canadian Health Services Research Foundation. (2006). Innovation through collaboration: working together for an evidence-informed health system. Report of the 8th Annual Invitational Workshop Canadian Health Services Research Foundation Vancouver, British Columbia.

Casanova, I. A., Batista, N. A., \& Ruiz-Moreno, L. (2015a). Formação para o trabalho em equipe na residência multiprofissional em saúde. ABCS Health Sci., 40(3), 229-233.

Casanova, I. A., Batista, N. A., \& Ruiz-Moreno, L. (2015b). Residência Multiprofissional em Saúde: percepção dos residentes sobre a Educação Interprofissional nas práticas colaborativas. Atas CIAIQ2015, 2, 368-370.

Casanova, I. A., Batista, N. A., \& Ruiz-Moreno, L. (2018). Interprofessional Education and shared practice in multiprofessional health residency programs. Interface (Botucatu), 22(1), 1325-37. 
Costa, B. F. (2018). A atenção básica como cenário de implementação da educação interprofissional em saúde: na perspectiva dos residentes (Dissertação de mestrado). Universidade Federal do Rio Grande do Norte, Natal, RN.

Costa, M. A. A educação interprofissional no contexto brasileiro: algumas reflexões. (2016). Interface (Botucatu. Impresso): comunicação, saúde, educação, 20(56), 197-198.

Dantas, B. T. (2020). Estratégias de ensino-avaliação voltadas ao desenvolvimento de competências para o trabalho em equipe na residência multiprofissional em saúde (Dissertação de mestrado). Universidade Federal do Rio Grande do Norte, Natal, RN.

Dias, I. M. A. V., Pereira, A. K., Batista, S. H. S. S., \& Casanova, I. A. (2016). A tutoria no processo de ensinoaprendizagem no contexto da formação interprofissional em saúde. Saúde Debate, 40(111), 257-267.

Evangelista, A. L. P., Frota, A. C., Torres, R. B. S., \& Barreto, I. C. H. C. (2018). Residência integrada em saúde mental: cuidado à rede de atenção psicossocial. Rev Bras Promoç Saúde, 31(4), 1-11.

Fernandes, D. (2006). Para uma teoria da avaliação formativa. Rev Port Educ., 19(2), 21-50.

Ferreira, M. L. S. M., Cotta, R. M. M., \& Oliveira, M. S. Construção Coletiva de Experiências Inovadoras no Processo Ensino-aprendizagem na Formação de Profissionais da Saúde. Revista Brasileira De Educação Médica, 33(2), 240-246, 2009.

Feuerwerker, L.C.M. (2009). No olho do furacão: contribuição ao debate sobre a residência multiprofissional em saúde. Interface, 13(28), 213-37.

Frossard, A. G. S., \& Silva, E. C. S. (2016). Experiência da residência multiprofissional em serviço social e cuidados paliativos oncológicos. R. Katál., 19(2), 281-288.

Gomes, A. T., Marques, J. S., Meneses, M. de O., Brandão, S. A. de S. M., \& Leal, S. R. M. de D. (2020). Potentialities and challenges of the Multiprofessional Residency Program for the training of nurses working in Primary Health Care. Research, Society and Development, 9(6).

Henrique, R. S., Moreira, A. C., Pinto, B. C. B. S., Collet, S. C., Benedito, S. R., \& Souza, V. L. C. (2019, outubro). Múltiplos olhares: a busca pela interprofissionalidade em uma equipe de residentes multiprofissionais em saúde da família no município do Rio de Janeiro (RJ). In Anais do $16^{\circ}$ Congresso Brasileiro de Assistentes Sociais, Brasília, DF.

Lago, L. P. M., Matumoto, S., Silva, S. S., Mestriner, S. F., \& Mishima, S. M. (2018). A análise de práticas profissionais como dispositivo para a formação na residência multiprofissional. Interface (Botucatu), 22(2), 1625-34.

Lago, L. P. M. (2019). Práticas profissionais na residência multiprofissional em saúde: uma pesquisa sócio-clínica. (Tese de doutorado). Escola de Enfermagem de Ribeirão Preto da Universidade de São Paulo, Ribeirão Preto, SP.

Leitão, B. F. B. (2018). Residência multiprofissional em cancerologia: expressões da integralidade do cuidado (Dissertação de mestrado). Universidade Federal do Ceará, Fortaleza, CE.

Lewgoy, A. M. B., Machado, R. N., Faber, T., Fagundes, M. I., \& Kuplich, N. M. (2019). A perspectiva interprofissional na residência integrada multiprofissional em saúde hospitalar. Clin Biomed Res., 39(1), 58-68.

Lima, I. C. B. F., \& Passos, I. C. F. (2019). Residências integradas em saúde mental: para além do tecnicismo. Trab. Educ. Saúde, 17(2), 1-22.

Medeiros, M. S. M. F. (2018). Educação para o trabalho interprofissional no contexto das residências em uma maternidade escola (Dissertação de mestrado). Universidade Federal do Rio Grande do Norte, Natal, RN.

Medina, A. G. (2016). Terapia ocupacional e a educação para a interprofissionalidade em residências multiprofissionais em saúde (Dissertação de mestrado). Universidade de São Paulo, São Paulo, SP.

Mendes, K. D. S., Silveira, R. C. C. P., \& Galvão, C. M. (2008). Revisão integrativa: método de pesquisa para a incorporação de evidências na saúde e na enfermagem. Texto \& Contexto - Enfermagem, 17(4), 758-764.

Miranda Neto, M. V., Leonello, V. M., \& Oliveira, M. A. C. (2015). Multiprofessional residency in health: a document analysis of political pedagogical projects. Rev Bras Enferm., 68(4), 586-93.

Miranda Neto, M. V. (2015). Limites e potencialidades da residência multiprofissional em saúde para a educação interprofissional (Dissertação de mestrado). Universidade de São Paulo, Escola de Enfermagem, São Paulo, SP.

Motta, L. B., \& Pacheco, L. C. (2014). Integrating medical and health multiprofessional residency programs: the experience in building an interprofessional curriculum for health professionals in Brazil. Education for Health, 27(1), 83-88.

Nascimento, A. C. B. do, \& Omena, K. V. M. de. (2021). Interprofessional Education in Multiprofessional Residency Programs in Health in Brazil: An integrative review. Research, Society and Development, 10(4).

Organização Mundial Da Saúde (OMS). (2010). Marco para Ação em Educação Interprofissional e Prática Colaborativa. Genebra: OMS.

Organização Pan-Americana da Saúde (OPAS.). (2017) Educação interprofissional na atenção à saúde: melhorar a capacidade dos recursos humanos para alcançar a saúde universal. Relatório da reunião. Bogotá, Colômbia. 7 a 9 de dezembro de 2016. Washington, D.C.

Peduzzi, M., Norman, I. J., Germani, A. C. C. G., Silva, J. A. M., \& Souza, G. C. (2013). Educação interprofissional: formação de profissionais de saúde para o trabalho em equipe com foco nos usuários. Rev Esc Enferm USP, 47(4), 977-83.

Perego, M. G., \& Batista, N. A. (2016). Aprendizagens Compartilhadas na Residência Multiprofissional em Saúde. Tempus, actas de saúde colet, $10(4), 39-51$. 
Research, Society and Development, v. 11, n. 2, e15711225510, 2022

(CC BY 4.0) | ISSN 2525-3409 | DOI: http://dx.doi.org/10.33448/rsd-v11i2.25510

Querido, D. L., Christoffel, M. M., Almeida, V. S., Esteves, A. P. V. S., Andrade, M., Leite, H. C. \& Rodrigues, E. C. (2020). Residência multiprofissional como estratégia para formação de recursos humanos na perspectiva interprofissional em saúde perinatal. Research, Society and Development, 9(9), 1-19.

Rebouças, R. R. M., Gondim, A. A., \& Pinheiro, J. A. M. (2019). (Im)Possibilidades de atuação interprofissional dos residentes multiprofissionais em contexto hospitalar. Rev. SBPH, 22(1), 51-71.

Reeves, S., Fletcher, S., Barr, H., Birch, I., Boet, S., Davies, N. \& Kitto, S. (2016). A BEME systematic review of the effects of interprofessional education: BEME Guide No. 39. Med Teach., 38(7), 656-68.

Rodrigues, T. F. (2016). Residências Multiprofissionais em Saúde: Formação ou trabalho? Serv. Soc. \& Saúde, 15(1), 71-82.

Sanches, M. V. (2019). A experiência do programa de residência multiprofissional em saúde mental com ênfase em dependência química: desafios para a educação interprofissional colaborativa (Dissertação de mestrado). Universidade de São Paulo, São Paulo, SP.

Santos, K. H., Marques, D., Pozzuto, L., \& Sideri, K. P. (2016). O trabalho de profissionais na residência multiprofissional em saúde. Rev. APS., 19(3), 495499.

Silva, A. S. (2017). Percepção de residentes e preceptores sobre a residência multiprofissional integrada em saúde com ênfase em onco-hematologia (Dissertação de mestrado). Universidade Federal de Ciências da Saúde de Porto Alegre, Porto Alegre, RS.

Soares, G. M. M. (2015). Colaboração e educação interprofessional na pós-graduação em saúde: estudo de caso da residência multiprofissional em saúde da família (Dissertação de mestrado). Universidade Federal do Ceará, Fortaleza, CE.

Steinert, Y. (2005). Learning together to teach together: Interprofessional education and faculty development. Journal of Interprofessional Care, Supplement, 1(19), 60-75. doi:10.1080/13561820500081778.

Uchôa-Figueiredo, L.R., Devicenzi, M. U., Dias, I. M. A. V., Correia, A. C., \& Vasconcelos, A. C. F. (2016). Gestão de um programa de Residência Multiprofissional. In L. R. Uchôa-Figueiredo, T. F. Rodrigues, I. M. A. V. Dias (Org.). Percursos interprofissionais: formação em serviços no Programa Residência Multiprofissional em Atenção à Saúde (1a. ed., Cap. 4, pp. 77-105). Porto Alegre: Rede Unida.

Vasconcelos, A. C. F., Stedefeldt, E., \& Frutuoso, M. F. P. (2016a). O que pensam os profissionais da Atenção Básica sobre a Residência Multiprofissional. In L. R. Uchôa-Figueiredo, T. F. Rodrigues, I. M. A. V. Dias (Org.). Percursos interprofissionais: formação em serviços no Programa Residência Multiprofissional em Atenção à Saúde (Cap. 19, pp. 343-358). Rede Unida.

Vasconcelos, A. C. F, Stedefeldt, E., \& Frutuoso, M. F. P. (2016b). Uma experiência de integração ensino-serviço e a mudança de práticas profissionais: com a palavra, os profissionais de saúde. Interface, Botucatu, 20(56), 147-158.

Wetzel, C., Kohlrausch, E. R., Pavani, F. M., Batistella, F. S., \& Pinho, L. B. (2018). Analysis of interprofessional in-service education in a Psychosocial Care Center. Interface (Botucatu), 22(2), 1729-1738. 